\title{
Body mass index and outcome in renal transplant recipients: a systematic review and meta-analysis
}

\author{
Jeffrey A Lafranca', Jan NM IJermans ${ }^{1}$, Michiel GH Betjes ${ }^{2}$ and Frank JMF Dor ${ }^{1 *}$
}

\begin{abstract}
Background: Whether overweight or obese end stage renal disease (ESRD) patients are suitable for renal transplantation (RT) is often debated. The objective of this review and meta-analysis was to systematically investigate the outcome of low versus high BMI recipients after RT.

Methods: Comprehensive searches were conducted in MEDLINE OvidSP, Web of Science, Google Scholar, Embase, and CENTRAL (the Cochrane Library 2014, issue 8). We reviewed four major guidelines that are available regarding (potential) RT recipients. The methodology was in accordance with the Cochrane Handbook for Systematic Reviews of Interventions and written based on the PRISMA statement. The quality assessment of studies was performed by using the GRADE tool. A meta-analysis was performed using Review Manager 5.3. Random-effects models were used.
\end{abstract}

Results: After identifying 5,526 studies addressing this topic, 56 studies were included. We extracted data for 37 outcome measures (including data of more than 209,000 RT recipients), of which 26 could be meta-analysed. The following outcome measures demonstrated significant differences in favour of low BMI (<30) recipients: mortality $(R R=1.52)$, delayed graft function $(R R=1.52)$, acute rejection ( $R R=1.17), 1-, 2-$, and 3-year graft survival $(R R=0.97,0.95$, and 0.97), 1-, 2-, and 3-year patient survival ( $R R=0.99,0.99$, and 0.99), wound infection and dehiscence $(\mathrm{RR}=3.13$ and 4.85$)$, NODAT $(\mathrm{RR}=2.24)$, length of hospital stay ( 2.31 days), operation duration ( 0.77 hours), hypertension $(\mathrm{RR}=1.35)$, and incisional hernia ( $R R=2.72$ ). However, patient survival expressed in hazard ratios was in significant favour of high BMI recipients. Differences in other outcome parameters were not significant.

Conclusions: Several of the pooled outcome measurements show significant benefits for 'low' BMI (<30) recipients. Therefore, we postulate that ESRD patients with a BMI $>30$ preferably should lose weight prior to RT. If this cannot be achieved with common measures, in morbidly obese RT candidates, bariatric surgery could be considered.

\section{Background}

As the incidence of overweight and obesity rises globally, so does the number of end stage renal disease (ESRD) patients with obesity [1]. Renal transplantation (RT) is the preferred therapeutic option for ESRD, however, whether obese patients are suitable for RT is often debated due to the higher risk of complications [2]. Several guidelines state that obesity is not considered an absolute contra-indication, although patients with a body mass index (BMI) above 40 or 45 should not be considered for RT $[3,4]$. On the other hand, the

\footnotetext{
* Correspondence: f.dor@erasmusmc.nl

'Department of Surgery, division of HPB \& Transplant Surgery, Erasmus MC, University Medical Center Rotterdam, 's Gravendijkwal 230, PO BOX 2040, 3000, CA Rotterdam, The Netherlands

Full list of author information is available at the end of the article
}

guidelines state that if the transplant surgeon determines that the body composition of the potential RT recipient does not constitute an increased surgical risk, the patient should be suitable for RT. However, this does not take into account that it is not only the surgery itself that poses a possible risk. Equally important is the incidence of post-transplant complications in the obese recipient. Observational studies in the general population have demonstrated that obesity is an independent risk factor for chronic vascular disease [5]. Obesity is also associated with a number of risk factors for chronic vascular disease, including hypertension, dyslipidaemia, and diabetes [6]. Of note, in general, the most important mortality and morbidity post-transplant is due to cardiovascular complications [7]. 
Other possible complications that have previously been associated with a higher incidence in obese recipients are delayed graft function (DGF), impaired graft survival, longer hospital stay, higher costs, higher incidence of new onset of diabetes after transplantation (NODAT) and increased mortality [8-11]. Intuitively, all overweight potential recipients should lose weight prior to transplantation. Usually, dietary restriction is applied under the supervision of a dietician. However, in most cases, the desired result is not achieved, caused by several factors such as the need for dialysis three times a week, a low exercise tolerance, and comorbidities. In case of peritoneal dialysis, patients are known to increase in weight because the dialysate contains a high concentration of dextrose [12]. The body absorbs some of this dextrose during the dwell, which can lead to weight gain. Bariatric surgery (in case of morbid obesity or a BMI $>35$ with one or more comorbidities) could be considered, as it has proven to be successful in weight reduction in non-ESRD patients $[13,14]$. Few studies are available regarding bariatric surgery pre- or posttransplantation in (morbidly obese) ESRD-patients, however these all show promising results [15-17]. As has been recently published by Gill et al. [18], the transplant community needs to realize that even obese RT recipients have a significant survival benefit from transplantation despite the reduced risk of death of obese dialysis patients.

Recently, Nicoletto et al. [19] carried out a systematic review and meta-analysis on the same topic, and conclude that obese patients have an increased risk for DGF. However, they only included 21 studies and did not include surgical outcome in these patients, which is an important topic in our opinion, as patients are frequently declined for RT because of the increased risk for surgical complications.

The aim of the present systematic review and metaanalysis is to give a more in-depth insight in (metabolic, survival, and surgical) outcome of low $(<30)$ versus high (>30) BMI recipients after RT.

\section{Methods}

All aspects of the Cochrane Handbook for Interventional Systematic Reviews were followed [20], and the manuscript was written according to the PRISMA statement [21].

\section{Literature search strategy}

Comprehensive searches were carried out in Embase, MEDLINE OvidSP, Web of Science, Google Scholar, CENTRAL (the Cochrane Library 2013, issue 5), and the Transplant Library. The search was performed for articles published until August 2014 relevant to outcome of kidney transplant recipients, both from a living or deceased donor. No language restriction was applied. Studies were included concerning patients that underwent RT, in which the recipients were divided according to BMI classification. As a cut-off value, a BMI of 30 was used to classify the included patients between 'low' $(<30)$ and 'high' (>30) BMI, according to the definitions of the World Health Organization [22]. Included outcome measures were: mortality (defined as death within follow-up of each study), patient survival at years 1,2 , and 3 , graft survival at years 1,2 , and 3 , primary nonfunction, DGF (in 10 out of 30 studies defined as the need for dialysis within 7 days of transplantation), acute rejection, chronic rejection, graft loss, estimated glomerular filtration rate, operation duration, length of stay, lymphoceles, wound infection, incisional hernia, hematoma, wound dehiscence, surgical adverse events, NODAT, hypertension, and CMV infection. Search terms for each search-engine are provided as Additional file 1 . Manual reference checks in included papers were performed to check for potentially missing studies.

\section{Guideline analysis}

In addition to the literature search, we searched for guidelines regarding (potential) RT recipients in order to put the studies and their results in perspective. Specifically, sections about (pre-operative) overweight or obesity and RT suitability were reviewed.

\section{Literature screening}

Studies were evaluated for inclusion by two independent researchers (JAL, FJMFD) for relevance to the subject. Study selection was accomplished through several phases of screening. First, studies were excluded if they were one of the following: case-reports, letters, editorials, case-series, animal studies, or if the abstract revealed no relevance to the subject. For publications without abstract, the full text was acquired. In the next phase, inclusion required that studies described two or more groups of RT recipients divided based on their BMI and described relevant outcome measures.

\section{Data extraction and critical appraisal}

The level of evidence of each paper was established using the GRADE tool [23]. The GRADE approach defines the quality of a body of evidence by consideration of within study risk of bias (methodological quality), directness of evidence, heterogeneity, precision of effect estimates, and risk of publication bias.

\section{Statistical analysis}

A meta-analysis was performed using Review Manager version 5.3 (The Nordic Cochrane Centre, Copenhagen, Denmark). Random-effects models were used to account 
for possible clinical heterogeneity. Depending on the outcome, results were presented in forest plots with risk ratios or mean differences. Overall effects were determined using the Z-test; 95\% CIs of these values were given and $P<0.05$ was considered statistically significant. Heterogeneity between studies was assessed by three methods. First, a Tau ${ }^{2}$ test and a $\chi^{2}$ test were performed for statistical heterogeneity, with a $P<0.1$ being considered statistically significant. Also, $I^{2}$ statistics were used to assess clinical heterogeneity, where an $I^{2}$ of $0 \%$ to $40 \%$ is considered as low heterogeneity, $30 \%$ to $60 \%$ as moderate heterogeneity, $50 \%$ to $90 \%$ as substantial heterogeneity, and $75 \%$ to $100 \%$ as considerable heterogeneity. Where studies reported on two or more high or low BMI groups, pooled mean estimates and standard deviations were calculated. Group means were weighted by the number of recipients in each study group. Funnel plot analysis was used to assess possible publication bias.

\section{Results}

We included four major guidelines that are currently available regarding (potential) RT recipients: the Kidney Disease Improving Global Outcomes (KDIGO) 'Clinical Practice Guideline for the Care of the Kidney Transplant Recipient' [24], 'Assessment of the Potential Kidney Transplant Recipient' ( $5^{\text {th }}$ edition, 2010) by the UK Renal Association [25], the 'Guideline on Kidney Donor and Recipient Evaluation and Perioperative Care' by the European Renal Best Practice (ERBP) guideline body [26], and Kidney Health Australia - Caring for Australasians with Renal Impairment (KHA-CARI): 'Recipient Assessment for Transplantation' and 'Obesity in renal transplantation' [27].

The KDIGO guidelines state that, in RT recipients, obesity is associated with cardiovascular events and mortality. Furthermore, they mention that there is little reason to believe that weight reduction measures are not equally effective in obese potential RT recipients as in the general population. However, there is some indication that pharmacological and surgical management of obesity may be more likely to cause harm than in the general population. They recommend that additional research is needed to determine the effect of bariatric surgery on outcomes in RT recipients.

The UK Renal Association guideline states that obese patients $\left(\mathrm{BMI}>30 \mathrm{~kg} / \mathrm{m}^{2}\right)$ present technical difficulties and are at increased risk of peri-operative complications. They should be screened rigorously for cardiovascular disease and each case should be considered individually. Although obesity is not an absolute contra-indication to transplantation, individuals with a BMI $>40 \mathrm{~kg} / \mathrm{m} 2$ are less likely to benefit from RT.
The ERBP guideline states that the association between BMI and patient survival after RT is controversial based on current literature. Furthermore, it is recommended that RT candidates with a BMI $>30 \mathrm{~kg} / \mathrm{m} 2$ should lose weight prior to RT.

The KHA-CARI guidelines recommend that obesity alone should not preclude a patient from being considered for RT. Furthermore, they state that as a pretransplant BMI $>40 \mathrm{~kg} / \mathrm{m} 2$ may not be associated with a survival advantage compared to remaining on dialysis, the suitability for transplant should be carefully assessed on an individual basis. Lastly, as patient and graft survival of obese transplant recipients may be mediated by comorbid factors, particularly cardiovascular, they recommend screening of obese transplant candidates for cardiovascular disease.

\section{Literature search results}

Out of 5,526 unique papers identified in the initial search, 56 studies were included. The PRISMA flow diagram for systematic reviews is presented in Figure 1. Data for 37 outcome measures were extracted (representing data of more than 209,000 recipients) of which 26 could be meta-analyzed. The characteristics of the included studies are presented in Table 1 . The assessment of the quality of the included studies is presented in Figure 2.

Although the search could have identified randomized controlled trials, only observational studies were found, as randomized controlled trials addressing this topic do not seem to be feasible.

\section{Survival outcome parameters}

Mortality The number of deceased patients was studied in 16 studies including a total of 5,489 RT recipients $[10,31,33,39,40,42,45,46,48,50,55,57,59,65,72,75]$. The overall risk ratio was 1.52 (confidence interval (CI), 1.142.03; $P=0.004, I^{2}=47 \% ; P=0.02$ ) for high BMI recipients (Figure 3). Five studies assessed the mortality rate in a regression model $[9,32,41,42,62]$. Overall, there were no significant differences with an overall hazard ratio of 1.01 (CI, 0.89-1.15; $P=0.87, I^{2}=87 \% ; P<0.01$ ). Massarweh et al. [55] also expressed mortality in odds ratios; OR, 1.39 (CI, 0.43-4.49; $P=0.58, I^{2}$ not applicable).

Patient survival (1-, 2-, and 3-year) One-year patient survival was analysed in 18 studies and showed better survival for low BMI recipients (risk ratio $(R R)=0.99$, CI, 0.99-0.99; $P<0.001, I^{2}=0 \%$; $\left.P=0.45\right)[2,9,10,28-31$, $34,39,44-46,50,51,54-56,62]$. At 2 years, seven studies showed a significant difference between recipient groups, again in favour of low BMI recipients $(\mathrm{RR}=0.99$, CI, 0.971.00; $\left.P=0.04, I^{2}=7 \% ; P=0.37\right)[10,29,44,45,50,62,78]$. The 3 -year patient survival was investigated in 12 studies, 


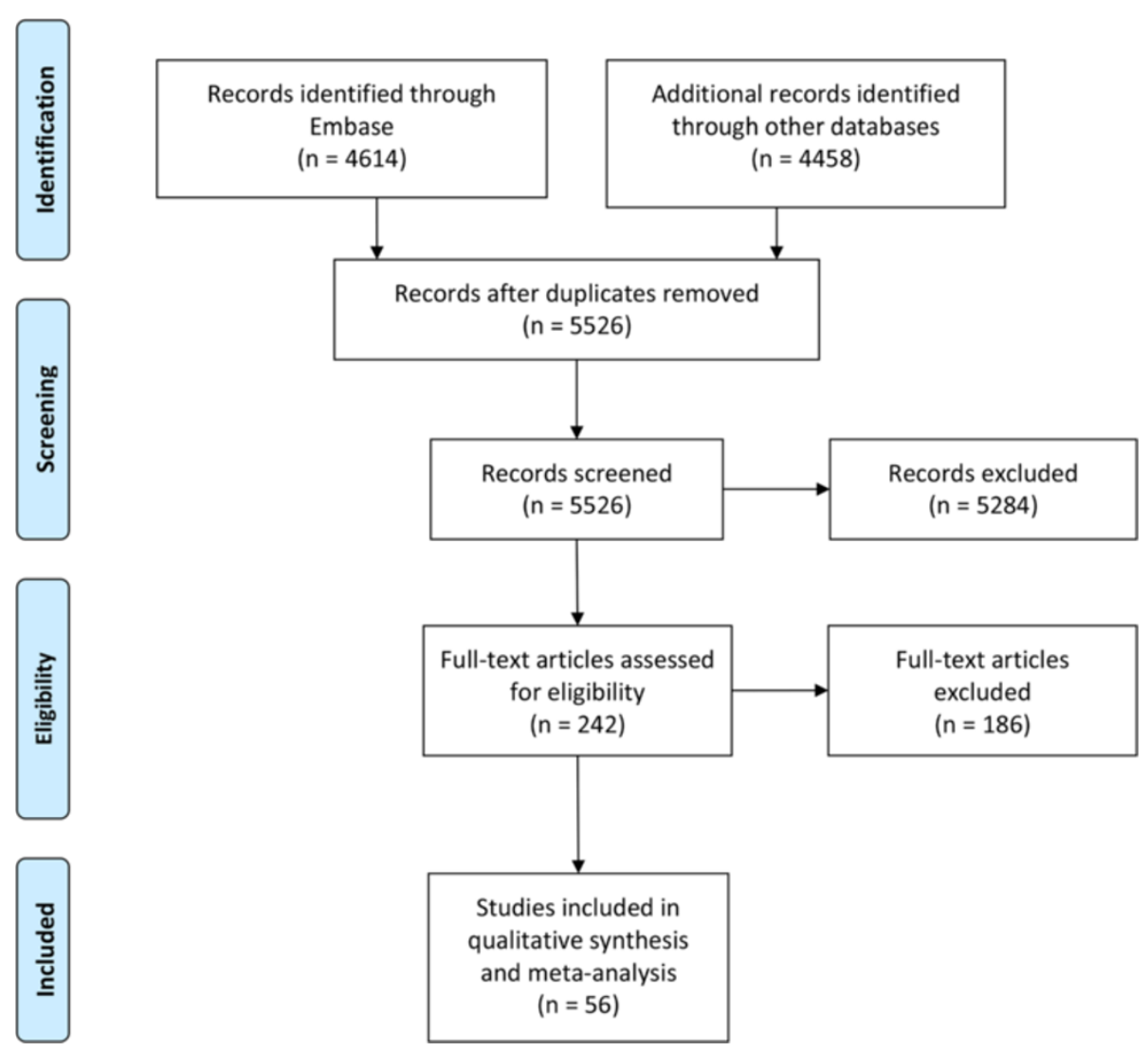

Figure 1 PRISMA (Preferred Reporting Items for Systematic Reviews and Meta-Analyses) flowchart of the systematic literature search.

showing significant differences with a risk ratio of 0.97 (CI, 0.95-0.99; $P=0.004, I^{2}=61 \% ; \mathrm{P}=0.003$; Figure 4) $[2,10,29-31,34,40,44,50,54,62,64]$. Interestingly, the five studies that included BMI in regression analyses showed that a higher BMI is associated with a higher patient survival with an overall hazard ratio of 0.93 (CI, 0.89-0.97; $P<0.001, I^{2}$ 0\%; $P=0.68$ ) $[2,29,30,51,53]$. Grosso et al. [42] calculated an odds ratio of 27.98 (CI, 3.25-240.89; $P=0.002, I^{2}$ not applicable) in high BMI recipients.

Graft survival (1-, 2-, and 3-year) Twenty-four studies investigated 1-year graft survival and showed a better graft survival in recipients with a low $B M I(R R=0.97$, CI, 0.96-0.99; $P<0.001, I^{2}=11 \% ; P=0.32$ ) $[9,10,28-31$, $33,39,44-46,48,50,51,53,54,56,57,59,60,62,63,68,75]$. Eleven studies assessed the 2-year graft survival [10,25,33,44, $45,48,50,57,62,63,78]$. The overall risk ratio was 0.95 (CI, 0.93-0.98; $P=0.002, I^{2}=30 \% ; P=0.16$ ). The 13 studies that analysed 3-year graft survival showed an overall risk ratio of 0.95 (CI, $0.91-0.98 ; P=0.006, I^{2}=50 \%$; $P=0.02) \quad[10,29-31,33,40,44,50,54,62-64,75]$. In each year studied, graft survival was in favour of low BMI recipients (Figure 5). Seven studies included BMI as a parameter in regression analyses showing no significant relation between BMI and graft survival. The overall hazard ratio was $1.00(\mathrm{CI}, 0.96-1.04 ; P=0.98$, $\left.I^{2} \quad 54 \% ; P=0.04\right) \quad[2,9,29,30,48,52,53]$. Grosso et al. [42] calculated an odds ratio $(\mathrm{OR}=0.98, \mathrm{CI}, 0.13-7.39$; $P=0.98, I^{2}$ not applicable).

\section{Kidney function outcome parameters}

Delayed graft function The incidence of DGF was assessed in 30 studies encompassing a total of 15,262 recipients $[1,4,28,29,31,33,34,36,38-40,42,43,46-48,50,53$, $56,57,59,60,64,66,69,71,75,77,78]$. The overall risk ratio was $1.52\left(\mathrm{CI}, 1.35-1.72 ; P<0.001, I^{2}=50 \% ; P=0.001\right.$; Figure 6). Six studies assessed DGF in ORs using a BMI of 30 as cut-off value $[2,8,32,35,58,73]$. The overall OR when pooling these studies was 1.38 (CI, 1.20-1.59; $\left.P<0.001, I^{2}=92 \% ; P<0.01\right)$. The pooled OR when using a BMI of 35 as a cut-off was 1.96 (CI, 1.69-2.28; $\left.P<0.001, I^{2}=32 \% ; P=0.23\right)[8,35,58]$.

Acute rejection The incidence of acute rejection was investigated in 22 studies $[4,10,28,33,36,38,39,43,46,48$, 50,55-57,59-61,64,69,72,75,76]. Twelve studies showed a lower risk ratio on acute rejection in low BMI recipients. 
Table 1 Overview of the included studies in the systematic review

\begin{tabular}{|c|c|c|c|c|}
\hline Reference & Country & Year & BMI groups & $\mathrm{n}$ \\
\hline \multirow[t]{2}{*}{ Aalten [9] } & The Netherlands & 2006 & $<30$ & 1,871 \\
\hline & & & $\geq 30$ & 196 \\
\hline \multirow[t]{4}{*}{ Abou-Jaoude [28] } & Lebanon & 2010 & $<18.5$ & 10 \\
\hline & & & $18.5-24.9$ & 62 \\
\hline & & & $25.0-29.9$ & 47 \\
\hline & & & $\geq 30$ & 16 \\
\hline \multirow[t]{2}{*}{ Bardonnaud [29] } & France & 2012 & $<30$ & 179 \\
\hline & & & $\geq 30$ & 21 \\
\hline \multirow[t]{4}{*}{ Begov [30] } & USA & 2013 & $18-24.9$ & 189 \\
\hline & & & $25-29.9$ & 169 \\
\hline & & & $30-34.9$ & 110 \\
\hline & & & $\geq 35$ & 78 \\
\hline \multirow[t]{3}{*}{ Bennett [31] } & USA & 2011 & $<30$ & 439 \\
\hline & & & $30.1-34.9$ & 109 \\
\hline & & & $>35$ & 89 \\
\hline \multirow[t]{4}{*}{ Cannon [2] } & USA & 2013 & $<30$ & 52,668 \\
\hline & & & $30.0-34.9$ & 15,010 \\
\hline & & & $35.0-39.9$ & 5,744 \\
\hline & & & $\geq 40$ & 1,561 \\
\hline \multirow[t]{4}{*}{ Chang [32] } & Australia & 2007 & $<18.5$ & 218 \\
\hline & & & $18.5-24.9$ & 2,719 \\
\hline & & & $25.0-29.9$ & 1,880 \\
\hline & & & $\geq 30$ & 867 \\
\hline \multirow[t]{2}{*}{ Chow [33] } & China & 2006 & $<25$ & 113 \\
\hline & & & $\geq 25$ & 37 \\
\hline \multirow[t]{4}{*}{ Cockbain [34] } & UK & 2012 & $<18.5$ & 731 \\
\hline & & & $18.5-24.9$ & (Combined) \\
\hline & & & $25.0-29.9$ & 421 \\
\hline & & & $\geq 30$ & 197 \\
\hline \multirow[t]{5}{*}{ Curran [35] } & USA & 2014 & $<20$ & 100 \\
\hline & & & $20-24.9$ & 429 \\
\hline & & & $25-29.9$ & 364 \\
\hline & & & $30-34.9$ & 184 \\
\hline & & & $\geq 35$ & 74 \\
\hline \multirow[t]{5}{*}{ Ditonno [36] } & Italy & 2011 & $<18.5$ & 68 \\
\hline & & & $18.6-24.9$ & 310 \\
\hline & & & $25.0-29.9$ & 143 \\
\hline & & & $30-34.9$ & 32 \\
\hline & & & $\leq 35$ & 10 \\
\hline \multirow[t]{5}{*}{ Dobbels [37] } & Belgium & 2008 & $<18.5$ & 2,156 \\
\hline & & & $18.6-24.9$ & 18,345 \\
\hline & & & $25.0-29.9$ & 15,040 \\
\hline & & & $30-34.9$ & 7,520 \\
\hline & & & $\leq 35$ & 3,401 \\
\hline
\end{tabular}

Table 1 Overview of the included studies in the systematic review (Continued)

\begin{tabular}{|c|c|c|c|c|}
\hline \multirow[t]{2}{*}{ Espejo [1] } & \multirow[t]{2}{*}{ Spain } & \multirow[t]{2}{*}{2003} & $<30$ & 40 \\
\hline & & & $\geq 30$ & 40 \\
\hline \multirow[t]{2}{*}{ Farooq [38] } & \multirow[t]{2}{*}{ USA } & \multirow[t]{2}{*}{2014} & $<36$ & 27 \\
\hline & & & $\geq 36$ & 27 \\
\hline \multirow[t]{3}{*}{ Furriel [39] } & \multirow[t]{3}{*}{ Portugal } & \multirow[t]{3}{*}{2011} & $18.5-24.9$ & 295 \\
\hline & & & $25.0-29.9$ & 127 \\
\hline & & & $\geq 30$ & 26 \\
\hline \multirow[t]{2}{*}{ Gill [40] } & \multirow[t]{2}{*}{ USA } & \multirow[t]{2}{*}{1993} & $<27$ & 85 \\
\hline & & & $>30$ & 85 \\
\hline Gill [41] & USA & 2013 & & Not reported \\
\hline \multirow[t]{5}{*}{ Gore [8] } & \multirow[t]{5}{*}{ USA } & \multirow[t]{5}{*}{2005} & $<18.5$ & 1,042 \\
\hline & & & $18.5-24.9$ & 12,089 \\
\hline & & & $25.0-29.9$ & 8,765 \\
\hline & & & $30-34.9$ & 3,891 \\
\hline & & & $\geq 35$ & 1,590 \\
\hline \multirow[t]{3}{*}{ Grosso [42] } & \multirow[t]{3}{*}{ Italy } & \multirow[t]{3}{*}{2012} & $<25$ & 122 \\
\hline & & & $25-30$ & 190 \\
\hline & & & $>30$ & 64 \\
\hline \multirow[t]{4}{*}{ Gusukuma [43] } & \multirow[t]{4}{*}{ Brazil } & \multirow[t]{4}{*}{2011} & $<30$ & 2,822 \\
\hline & & & $30-34.9$ & 185 \\
\hline & & & $35-39.9$ & 43 \\
\hline & & & $\geq 40$ & 4 \\
\hline \multirow[t]{2}{*}{ Halme [44] } & \multirow[t]{2}{*}{ Finland } & \multirow[t]{2}{*}{1995} & $20-25$ & 235 \\
\hline & & & $>30$ & 47 \\
\hline \multirow[t]{3}{*}{ Holley [45] } & USA & 1990 & $\leq 27$ (male) & 50 \\
\hline & & & $\leq 25$ (female) & \\
\hline & & & $\geq 30$ & 46 \\
\hline Howard [46] & USA & 2002 & $<25$ & 457 \\
\hline & & & $25-29.9$ & 278 \\
\hline & & & $\geq 30$ & 98 \\
\hline Impedovo [47] & Italy & 2012 & $<18.5$ & 98 \\
\hline & & & $18.6-24.9$ & 428 \\
\hline & & & $25-29.9$ & 179 \\
\hline & & & $\geq 30$ & 58 \\
\hline Johnson [48] & Australia & 2002 & $\leq 30$ & 434 \\
\hline & & & $>30$ & 59 \\
\hline Kamali [49] & Iran & 2010 & $<30$ & 146 \\
\hline & & & $>30$ & 34 \\
\hline Karabicak [50] & USA & 2011 & $<20$ & 74 \\
\hline & & & $20-24.9$ & 215 \\
\hline & & & $25-29.9$ & 193 \\
\hline & & & $30-34.9$ & 99 \\
\hline & & & $\geq 35$ & 61 \\
\hline
\end{tabular}


Table 1 Overview of the included studies in the systematic review (Continued)

\begin{tabular}{|c|c|c|c|c|}
\hline \multirow[t]{3}{*}{ Lynch [51] } & USA & 2009 & $<20$ & 33 \\
\hline & & & $20-30$ & 491 \\
\hline & & & $\geq 30$ & 345 \\
\hline \multirow[t]{3}{*}{ McGee [52] } & USA & 2008 & $<25$ & Not reported \\
\hline & & & $25-29$ & \\
\hline & & & $\geq 30$ & \\
\hline \multirow[t]{4}{*}{ Marcen [53] } & Spain & 2007 & $<18.5$ & 63 \\
\hline & & & $18.5-24.9$ & 617 \\
\hline & & & $25-29.9$ & 255 \\
\hline & & & $\geq 30$ & 65 \\
\hline \multirow[t]{2}{*}{ Marks [54] } & USA & 2004 & $\leq 28$ & 224 \\
\hline & & & $\geq 35$ & 23 \\
\hline \multirow[t]{2}{*}{ Massarweh [55] } & USA & 2005 & $<30$ & 137 \\
\hline & & & $\geq 30$ & 56 \\
\hline \multirow[t]{2}{*}{ Mehta [56] } & USA & 2007 & $<30$ & 37 \\
\hline & & & $\geq 30$ & 16 \\
\hline \multirow[t]{2}{*}{ Meier-Kriesche [10] } & USA & 1999 & $\leq 25$ & 240 \\
\hline & & & $>25$ & 165 \\
\hline \multirow[t]{2}{*}{ Modlin [57] } & USA & 1997 & $<27$ & 127 \\
\hline & & & $>30$ & 127 \\
\hline \multirow[t]{6}{*}{ Molnar [58] } & USA & 2011 & $\leq 19.9$ & Not reported \\
\hline & & & $20-21.99$ & \\
\hline & & & $22-24.99$ & \\
\hline & & & $25-29.99$ & \\
\hline & & & $30-34.99$ & \\
\hline & & & $\geq 35$ & \\
\hline \multirow[t]{4}{*}{ Moreira [59] } & Brazil & 2013 & $<18.5$ & 31 \\
\hline & & & $18.5-24.9$ & 248 \\
\hline & & & $25-29.9$ & 120 \\
\hline & & & $\geq 30$ & 48 \\
\hline \multirow[t]{2}{*}{ Papalia [60] } & Italy & 2010 & $18.5-25$ & 110 \\
\hline & & & $25-30$ & 84 \\
\hline \multirow[t]{2}{*}{ Patel [61] } & USA & 2011 & $<30$ & 315 \\
\hline & & & $\geq 30$ & 160 \\
\hline \multirow[t]{2}{*}{ Pieloch [62] } & USA & 2014 & $18.5-24.9$ & 24,077 \\
\hline & & & $35-40$ & 6,055 \\
\hline \multirow[t]{3}{*}{ Pirsch [63] } & USA & 1995 & $<27.5$ & 466 \\
\hline & & & $27.5-30$ & 59 \\
\hline & & & $>30$ & 59 \\
\hline \multirow[t]{3}{*}{ Powers [64] } & USA & 2010 & $<25$ & 34 \\
\hline & & & $25-30$ & 34 \\
\hline & & & $>30$ & 20 \\
\hline
\end{tabular}

Table 1 Overview of the included studies in the systematic review (Continued)

\begin{tabular}{|c|c|c|c|c|}
\hline \multirow[t]{4}{*}{ Rais-Jalali [65] } & \multirow[t]{4}{*}{ Iran } & \multirow[t]{4}{*}{2005} & $<20$ & 56 \\
\hline & & & $20-24.9$ & 86 \\
\hline & & & $25-29.9$ & 28 \\
\hline & & & $\geq 30$ & 12 \\
\hline \multirow[t]{5}{*}{ Rajab [66] } & \multirow[t]{5}{*}{ USA } & \multirow[t]{5}{*}{2007} & $<25$ & 411 \\
\hline & & & $25-29.9$ & 416 \\
\hline & & & $30-34.9$ & 292 \\
\hline & & & $35-39.9$ & 106 \\
\hline & & & $>40$ & 80 \\
\hline \multirow[t]{4}{*}{ Ravindra [67] } & \multirow[t]{4}{*}{ USA } & \multirow[t]{4}{*}{2013} & $<25$ & \multirow[t]{4}{*}{ Not reported } \\
\hline & & & $25-29$ & \\
\hline & & & $30-34$ & \\
\hline & & & $\geq 35$ & \\
\hline \multirow[t]{2}{*}{ Schwarznau [68] } & \multirow[t]{2}{*}{ USA } & \multirow[t]{2}{*}{2008} & $<30$ & 56 \\
\hline & & & $>30$ & 25 \\
\hline \multirow[t]{2}{*}{ Singh [69] } & \multirow[t]{2}{*}{ Canada } & \multirow[t]{2}{*}{2005} & $\leq 30$ & 35 \\
\hline & & & $>30$ & 33 \\
\hline \multirow[t]{4}{*}{ Tang [70] } & \multirow[t]{4}{*}{ USA } & \multirow[t]{4}{*}{2011} & $18-24.9$ & 136 \\
\hline & & & $25-29.9$ & 116 \\
\hline & & & $30-34.9$ & 66 \\
\hline & & & $\geq 35$ & 54 \\
\hline \multirow[t]{5}{*}{ Tremblay [71] } & \multirow[t]{5}{*}{ USA } & \multirow[t]{5}{*}{2014} & $<20$ & 32 \\
\hline & & & $20-24.9$ & 119 \\
\hline & & & $25-29.9$ & 149 \\
\hline & & & $30-34.9$ & 110 \\
\hline & & & $\geq 35$ & 57 \\
\hline \multirow[t]{2}{*}{ Turner [4] } & \multirow[t]{2}{*}{ USA } & 2007 & $<30$ & 753 \\
\hline & & & $\geq 30$ & 241 \\
\hline Walczak [72] & USA & 2010 & $<30$ & 61 \\
\hline & & & $>30$ & 46 \\
\hline Weissenbacher [73] & Austria & 2012 & $<25$ & 746 \\
\hline & & & $>25$ & 367 \\
\hline Wolyniec [74] & Poland & 2011 & $<30$ & 29 \\
\hline & & & $\geq 30$ & 29 \\
\hline Yamamoto [75] & USA & 2002 & $<30$ & 28 \\
\hline & & & $>30$ & 28 \\
\hline Zaydfudim [76] & USA & 2010 & $18.5-24.9$ & 154 \\
\hline & & & $25-29.9$ & 192 \\
\hline & & & $30-34.9$ & 80 \\
\hline & & & $\geq 35$ & 38 \\
\hline Zrim [77] & Australia & 2012 & $<18.5$ & 10 \\
\hline & & & $18.5-24.9$ & 182 \\
\hline & & & $25-29.9$ & 194 \\
\hline & & & $30-34.9$ & 93 \\
\hline & & & $\geq 35$ & 29 \\
\hline
\end{tabular}




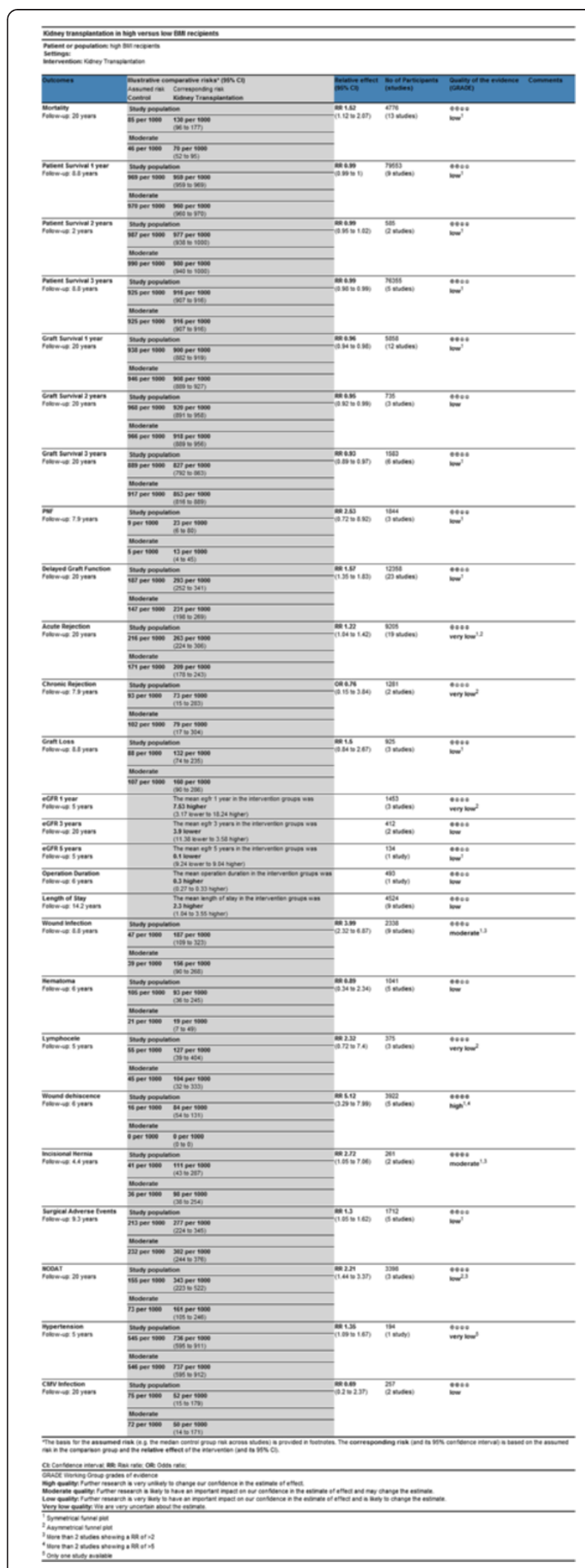

Figure 2 Summary of findings table of extended criteria in live kidney donation generated by the GRADE tool.
The overall risk ratio, including 10,170 recipients, was 1.17 (CI, 1.01-1.37; $P=0.04, I^{2}=38 \% ; P=0.04$; Figure 7). Gore et al. [8] assessed the incidence of acute rejection in OR as 1.19 (CI, 1.11-1.28; $P<0.001, I^{2}$ not applicable).

Other outcome parameters showing no significant differences in kidney function outcome parameters are outlined in Table 2.

\section{Surgical outcome parameters}

Operation duration Only three studies investigated the operation duration in low versus high BMI recipients, showing a mean difference of 0.77 hours (CI, 0.15-1.40), with a statistically significant difference $\left(P=0.02, I^{2}=87 \%\right.$; $P<0.01$; Figure 8) [40,45,48].

Length of stay The length of hospital stay was assessed in 11 studies [28,29,39,40,43,45,54,56,57,69,78]. All studies but two showed a mean length of stay in favour of low BMI recipients $[39,40]$. The overall mean difference was 2.31 days (CI, 0.93-3.69; $P=0.001, I^{2}=48 \%, P=0.04$; Figure 8).

Wound infection The incidence of wound infections was studied in 13 studies with a total of 4,504 recipients $[31,40,45,48,51,54-56,59,61,63,69,72,78]$. The overall risk ratio of this outcome was $3.13(\mathrm{CI}, 2.08-4.71 ; P<0.001$, $I^{2}=65 \% ; P<0.01$; Figure 9).

Incisional hernia Two studies assessed the incidence of incisional hernias [55,69]. The overall risk ratio was 2.72 (CI, 1.05-7.06; $P=0.04, I^{2}=0 \% ; P=0.82$; Figure 9).

Wound dehiscence Six studies reported the incidence of wound dehiscence including 3,922 recipients [29,43, $48,51,69,72$ ]. The overall risk ratio was 4.85 (CI, 3.257.25; $P<0.001, I^{2}=0 \% ; P=0.75$; Figure 10 ).

Surgical adverse events Five studies investigated surgical adverse events, such as urologic, vascular, and haemorrhagic complications $[28,36,39,74,77]$. The overall risk ratio was $1.30\left(\mathrm{CI}, 1.05-1.62 ; P=0.02, I^{2}=0 \% ; P=0.65\right.$; Figure 10).

Other outcome parameters showing no significant differences in surgical outcome parameters are outlined in Table 3.

\section{Metabolic outcome parameters}

NODAT Six studies including 4,111 recipients investigated the incidence of new onset diabetes after transplantation $[33,40,43,45,59,60]$. Overall, a risk ratio of 2.24 (CI, $1.46-3.45 ; P<0.001, I^{2}=53 \% ; P=0.06$ ) was found. 


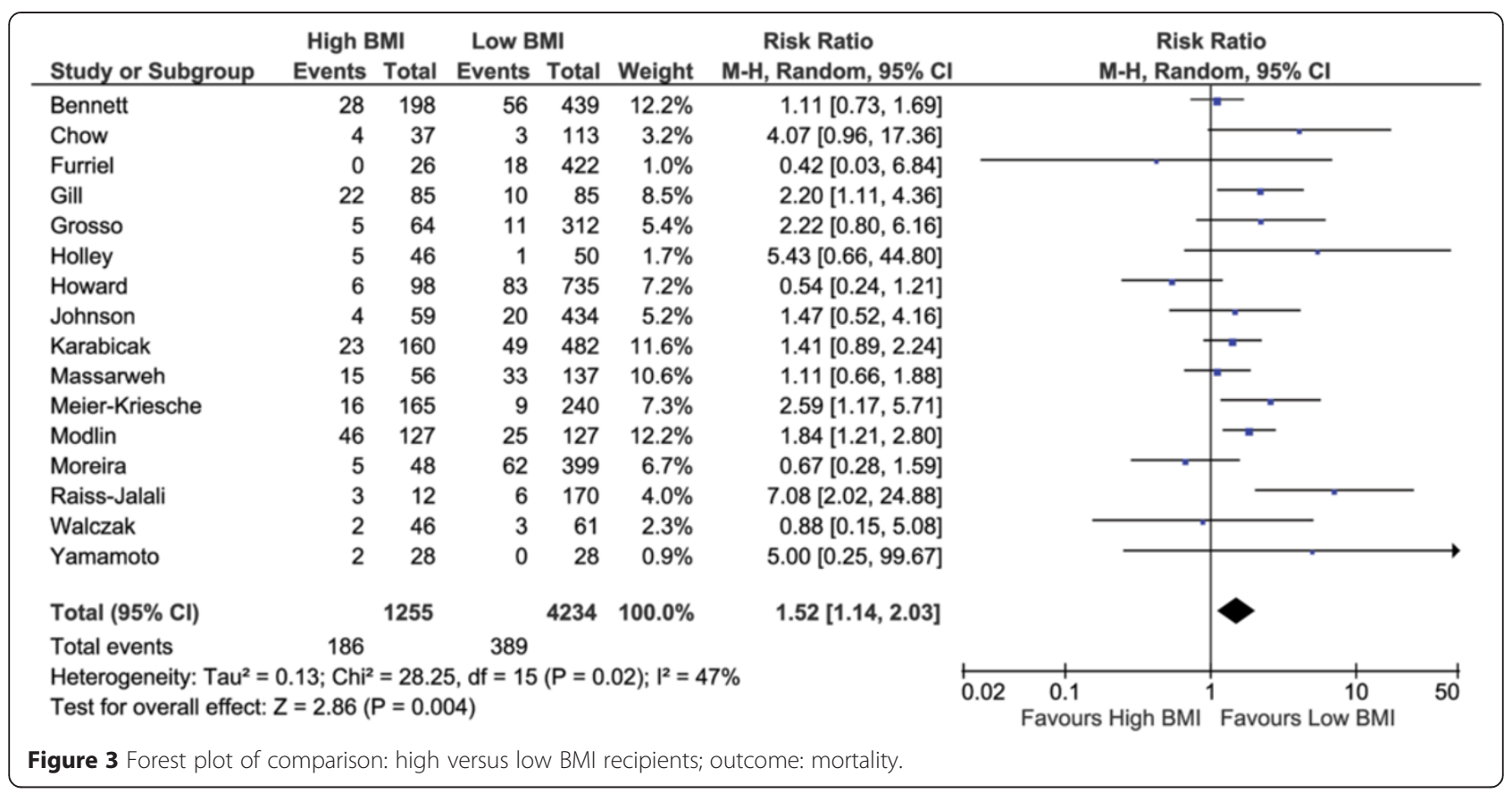

Hypertension Only one study assessed the incidence of hypertension in different BMI groups including 194 patients [60]. High BMI recipients had a higher risk on hypertension with a risk ratio of 1.35 (CI, 1.09-1.67; $P=0.005, I^{2}$ not applicable).

\section{Other outcome parameters}

Cytomegalovirus (CMV) infection The incidence of CMV infection was addressed in two studies [33,72]. Overall, the risk ratio was 0.69 (CI, 0.20-2.37; $P=0.56$, $\left.I^{2}=14 \% ; P=0.28\right)$ in favour of low BMI recipients.

\section{Discussion}

With this meta-analysis, we aimed to determine whether guidelines or policy should be revised with respect to suitability for RT of overweight and obese (potential) recipients, since this is often debated. There are several central questions behind this need for additional insight. Should obese ESRD-patients be transplanted at all? Are we and are these patients aware of all possible risks? Should we emphasize the need for weight loss, or even advise bariatric surgery before RT, and to whom?

The worldwide prevalence of obesity is rising, leading to an increasing number of patients with cardiovascular comorbidity, diabetes (metabolic syndrome) and, consequently, ESRD [79-81]. As RT is the golden standard in treating these patients, a good understanding of the consequences of transplanting overweight and obese ESRD-patients is needed. Several reviews have been written regarding this topic
[82-93]. The KDIGO-guidelines state that observational studies report an association between obesity and mortality in RT recipients. The present study is the first meta-analysis investigating several (metabolic, survival, and surgical) outcome measures, and pooling data from a large number of studies $(n=56$, including over 209,000 recipients).

Nicoletto et al. [19] recently published a systematic review and meta-analysis regarding this very subject. Their main finding was that recipient obesity is associated with an increased rate of DGF and that there was no association between obesity and acute rejection. One of the limitations of their study is that they included only 21 studies, whereas we included 56 publications. This could be explained by the fact that fewer databases have been searched by the authors (MEDLINE, EMBASE, and the Cochrane Library) than we did (Web of Science, Google Scholar, and the Transplant Library). Furthermore, the authors did not describe if any study was excluded based on the quality assessment of the Newcastle-Ottawa Quality Assessment Scale or the GRADE tool. Interestingly, the authors observed that studies published after 2003 show no differences in survival between BMI groups. Although they state that 2003 was used as a cut-off because of the fact that included patients were transplanted before 2000, they do not provide an explanation as to why obesity would pose a problem before 2000. In our opinion, other factors may contribute to this result, such as the fact that live kidney donation has increased over the years, providing 


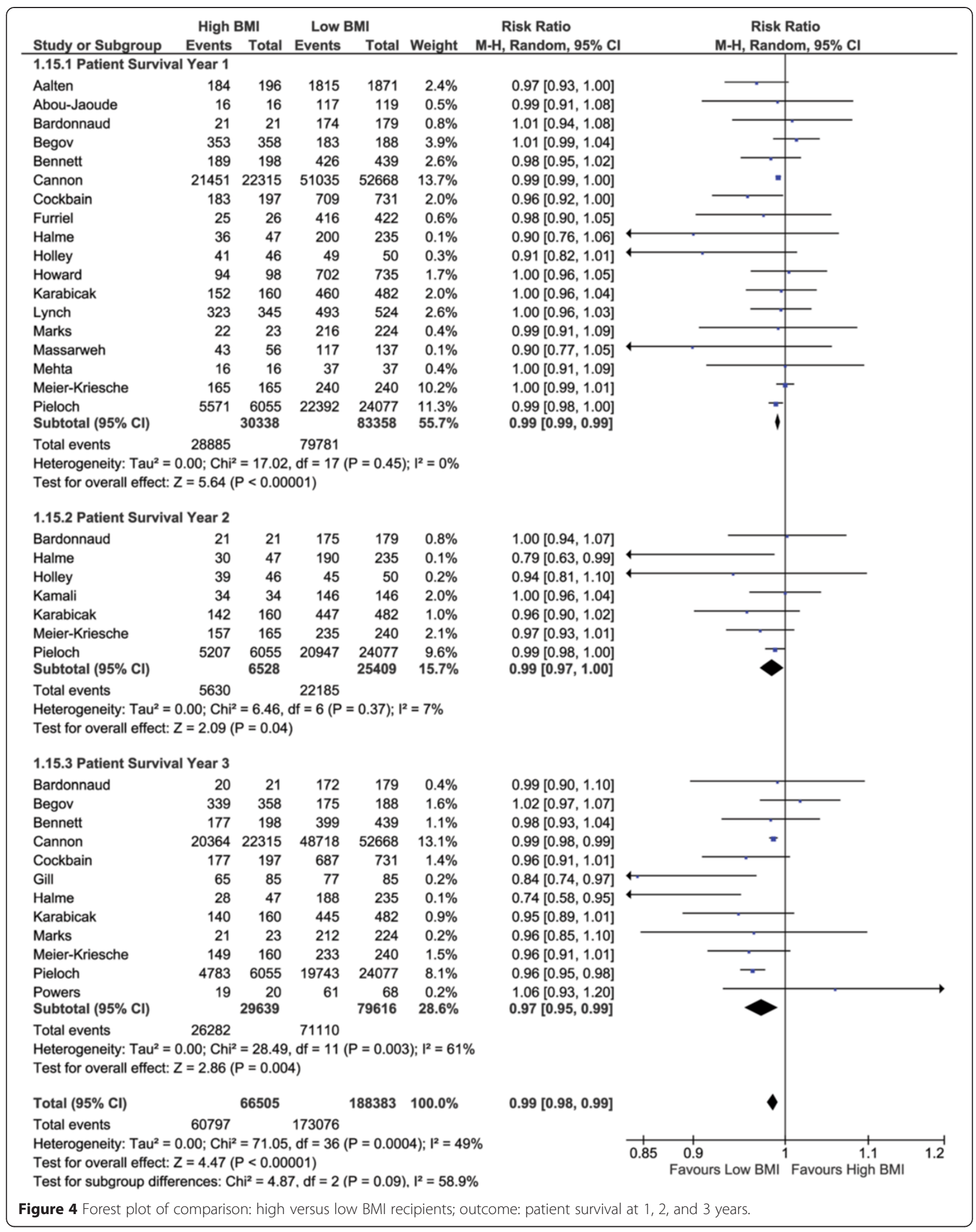




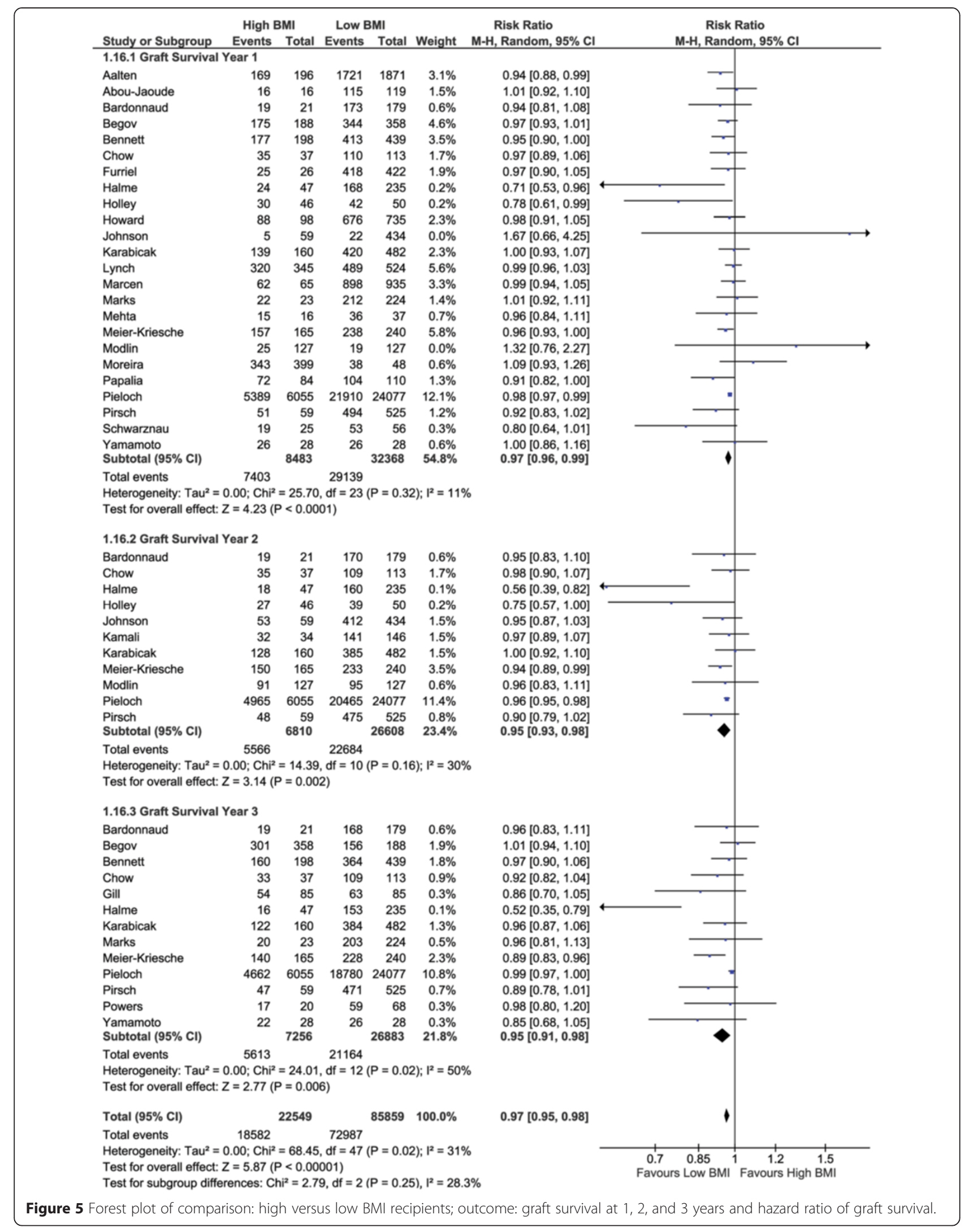




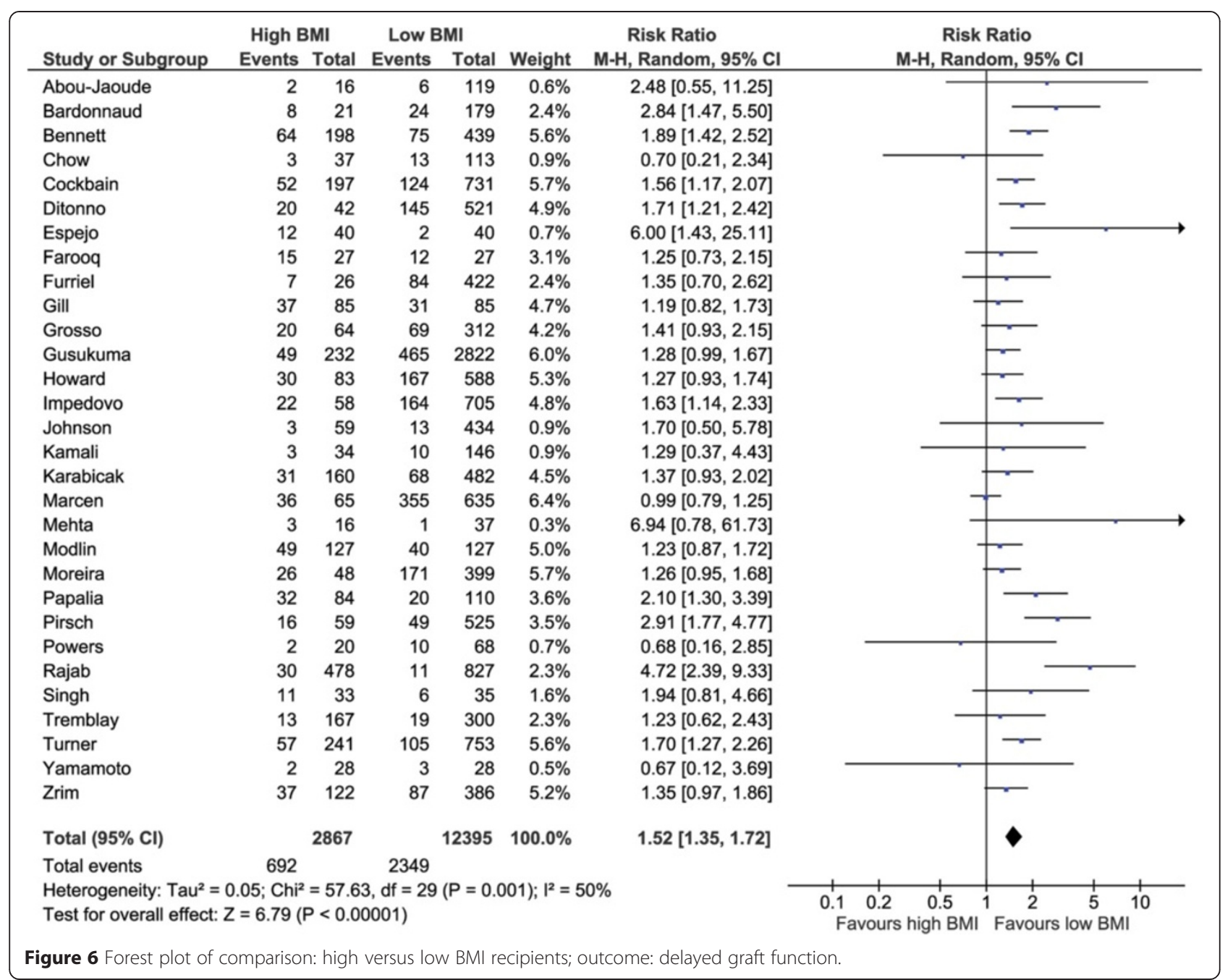

better quality grafts resulting in increased graft and, thus, patient survival. Moreover, they did not analyse surgical outcome measures as wound infection and dehiscence. In our opinion these are important outcomes that should also be included in the informed consent procedure for the recipients. Finally, we have included a meta-analysis of hazard ratios of graft and patient survival in the included studies, showing more clearly that the BMI itself may not be the cause of worse outcome in RT recipients but rather other comorbidities associated with obesity such as diabetes or (cardio-)vascular disease. Perhaps different lifestyle recommendations should be provided to patients who remain on dialysis versus those who will be transplanted [94].

Our results clearly show that, in recipients with a higher BMI, graft and patient survival are worse, at least up to 3 years after transplantation. Interestingly, in regression analyses, regarding patient survival, having a higher BMI seems to be associated with a higher patient survival, and regarding graft survival there appears to be no significant relation with the BMI. This could be explained by the 'obesity paradox', an interesting phenomenon that has been described for haemodialysis patients [93], suggesting that patients on haemodialysis with a higher BMI tend to have an improved survival benefit. However, the improved survival benefit is associated with higher costs, more complications, and worse outcome after transplantation [95]. On the other hand, and perhaps most importantly, obese RT recipients still demonstrate significant survival benefit from transplantation compared to dialysis [18].

The kidney function outcome parameters show that the incidence of DGF and acute rejection is higher in high BMI recipients. A possible explanation is that the operation duration is longer in recipients with a higher BMI, which in itself is associated with higher DGF-rates [96]. The increased incidence of acute rejection might be explained by the fact that obesity is 


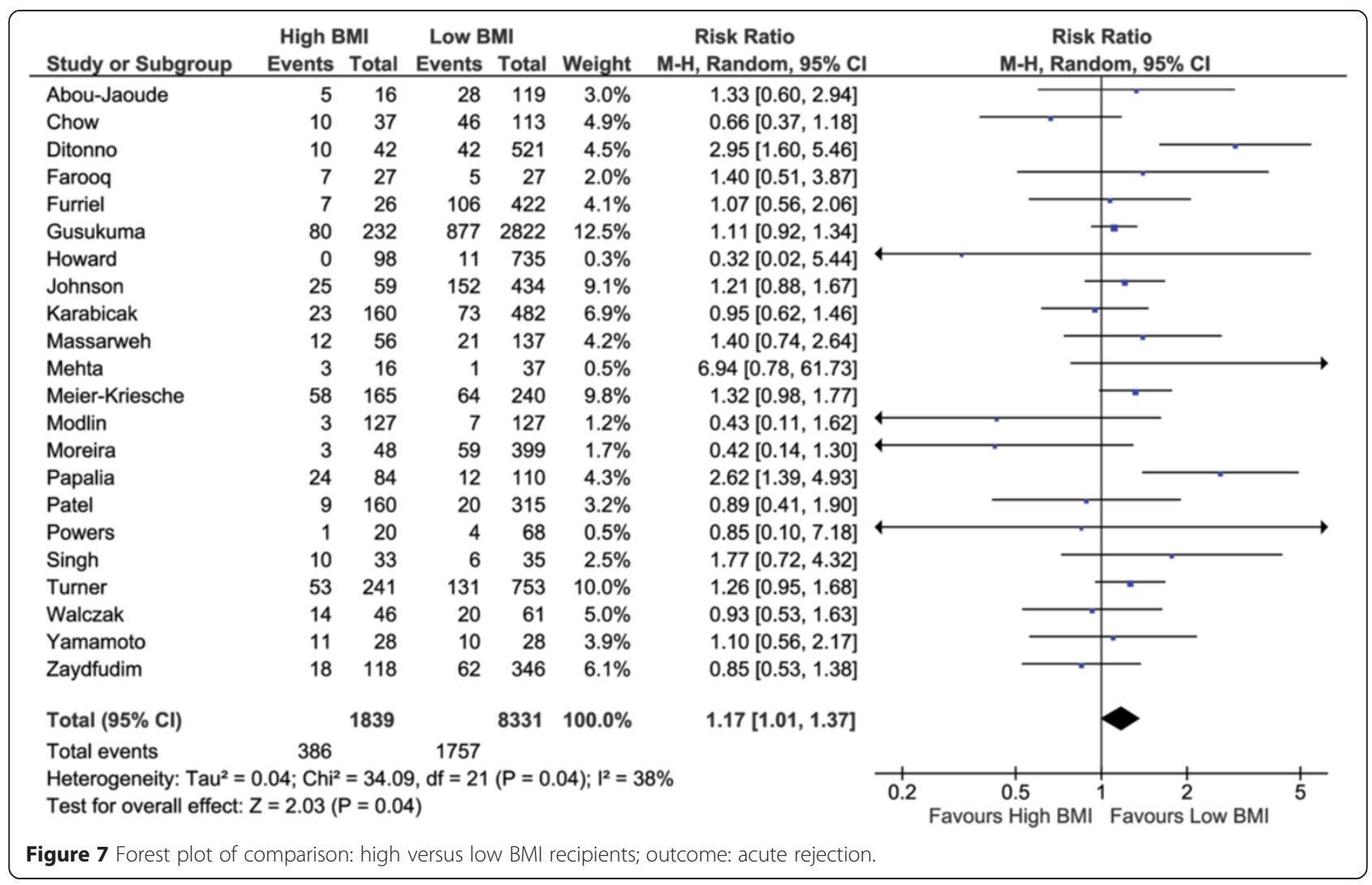

linked to inflammation and modified immune responses, potentially impacting allorecognition and alloimmunity [97]. Another possibility is the increased finding of (not clinically relevant) rejection because of the higher incidence of biopsies in case of DGF.

Regarding the metabolic outcome parameters, increasing BMI shows a significant correlation with the development of NODAT and hypertension, which is not surprising, knowing that overweight and obesity are common risk factors for developing these comorbidities [92,98].

Table 2 Outcome parameters with no significant differences

\begin{tabular}{llll}
\hline $\begin{array}{l}\text { Outcome } \\
\text { parameter }\end{array}$ & Studies & RR (Cl) & $P$ value \\
\hline $\begin{array}{l}\text { Primary non } \\
\text { function }\end{array}$ & $3[36,39,46]$ & $2.53(0.72-8.92)$ & 0.15 \\
Chronic rejection & $2[39,46]$ & $0.18-3.54$ & 0.76 \\
Graft loss & $5[42,48,51,59,75]$ & $1.14(0.87-1.50)$ & 0.34 \\
& & Mean difference (Cl) & \\
eGFR year 1 & $3[4,28,70]$ & $7.53 \mathrm{~mL} / \mathrm{min}(-3.17-18.24)$ & 0.17 \\
eGFR year 3 & $2[33,70]$ & $-3.90 \mathrm{~mL} / \mathrm{min}(-11.38-3.58)$ & 0.31 \\
eGFR year 5 & $1[70]$ & $-0.10 \mathrm{~mL} / \mathrm{min}(-0.24-9.04)$ & 0.98 \\
\hline
\end{tabular}

eGFR, Estimated glomerular filtration rate; $\mathrm{RR}$, Risk ratio; $\mathrm{Cl}$, Confidence interval.
All surgical outcome measures are significantly in favour of recipients with a low BMI, with exception of the incidence of hematoma and lymphoceles. A possible explanation could be that the latter two complications are not necessarily influenced by overweight or body composition, in contrast to wound dehiscence or hernias $[99,100]$.

Although a large part of our systematic review concerns long-term outcome measures, we should bear in mind that the perioperative (surgical) outcome measures are of great importance. Many RT candidates with a high BMI are declined because the concern of possible surgical difficulties and inherent complications. As confirmed by the results of the metaanalysis, this concern is justified. Therefore, high BMI RT candidates should be referred to tertiary referral centres to centralise knowledge about and experience with this patient category, especially on a transplant surgical level. Additionally, it is another motivator to encourage RT candidates to lose weight prior to transplantation, ideally several years before the operation. Nephrologists can play a crucial and proactive role in this process.

In summary, we conclude that obesity prior to RT leads to impaired outcome after RT. Losing weight prior to transplantation might be of great importance, 


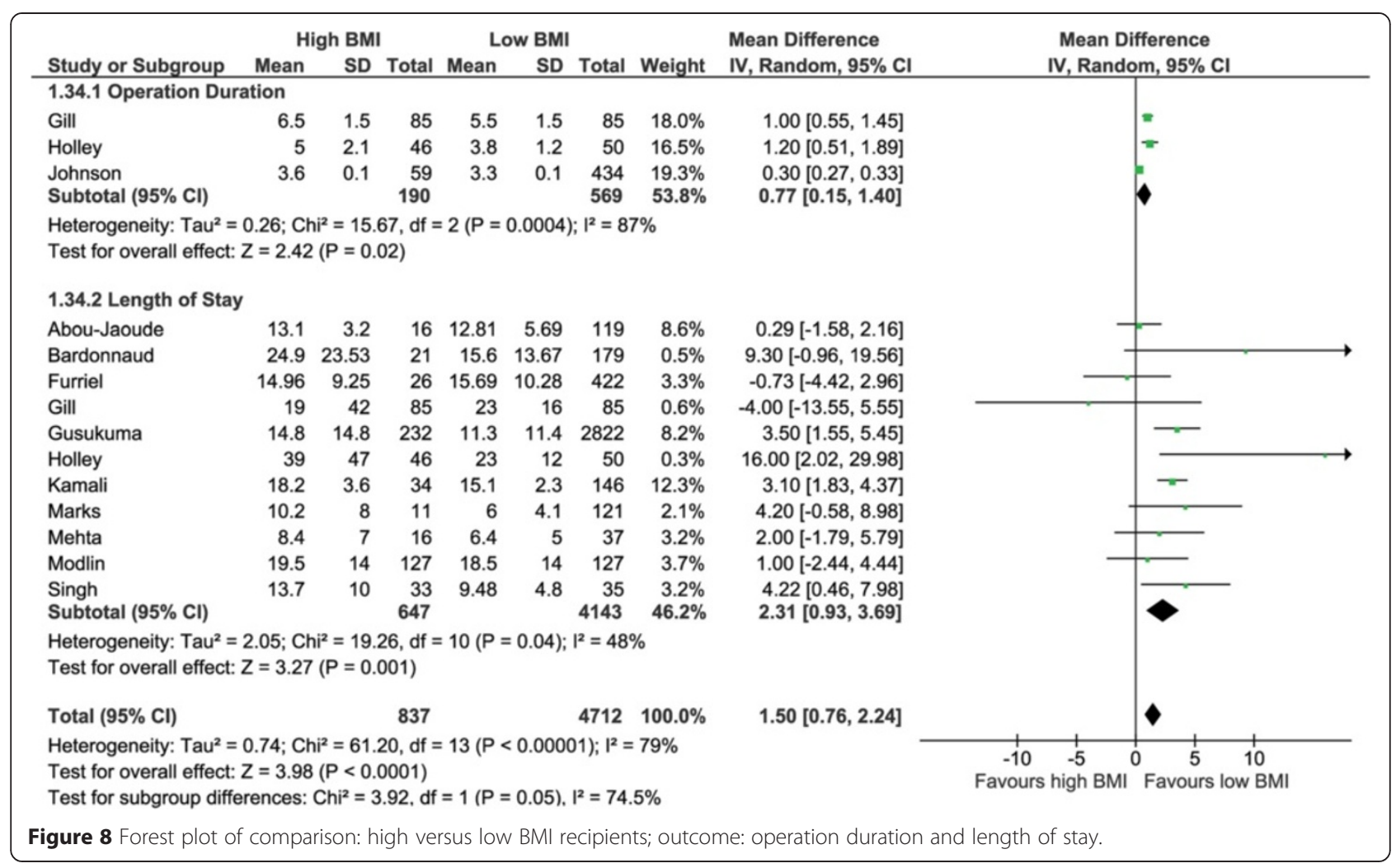

although it is unclear whether this is advantageous for ESRD patients who remain dependent on dialysis [101]. However, one should bear in mind that, even if sufficient weight loss cannot be achieved before transplantation, transplantation still leads to enormous advantages in terms of survival, health, and quality of life [18]. We have recently performed a study showing that patients who are deemed unsuitable for RT because of high BMI in one centre have excellent outcome when transplanted in a tertiary high-volume centre (Glijn et al., manuscript in preparation). For overweight or obese recipients that will be transplanted, conventional methods to lose weight, such as dietary advice, might not lead to the desired (or sufficient) effect $[16,46,102]$. Even though some weight loss might be achieved, after transplantation, the weight is often regained, possibly caused by the metabolic changes that may result in better nutrient absorption and/or reduced energy expenditure with improved renal function after transplantation. Furthermore, the increased quality of life may lead to a larger food intake [94,103].

Another, more effective, method to lose weight prior to or post-transplantation is bariatric surgery. Some studies have already been performed showing promising results [15-17,104-107]. Furthermore, it is already stated by several guidelines that any person with a BMI above 40 , or a BMI higher than 35 with comorbidities, should be advised to undergo bariatric surgery [108-110] since it has proven to resolve obesity-related comorbidities like diabetes, hypertension, sleep apnoea, and asthma and reduces mortality rates. An issue of concern, however, is whether an ESRD-patient is fit enough to undergo a risk reducing operation with the risk of complications in itself. In general, the complication and mortality rates after bariatric surgery have declined greatly over the years to about $0.3 \%$ [111]. A few studies on bariatric surgery in ESRD-patients show low complication and 90-day mortality rates close to $0 \%[15,16,112-114]$. This is important to acknowledge because survival of patients on dialysis is far worse compared to the survival after RT. [18] Therefore, every possible RT candidate should be carefully assessed to see if possible complications of bariatric surgery, although being very low, would not pose a risk for the transplantation. In our opinion, every obese recipient should be informed about this possibility, being aware of possible risks. A clinical trial is ongoing to investigate whether bariatric surgery before RT has benefits (ClinicalTrials.gov, number NCT01913392).

\section{Limitations}

It has to be acknowledged that a systematic review and meta-analysis can only be as good as the quality 


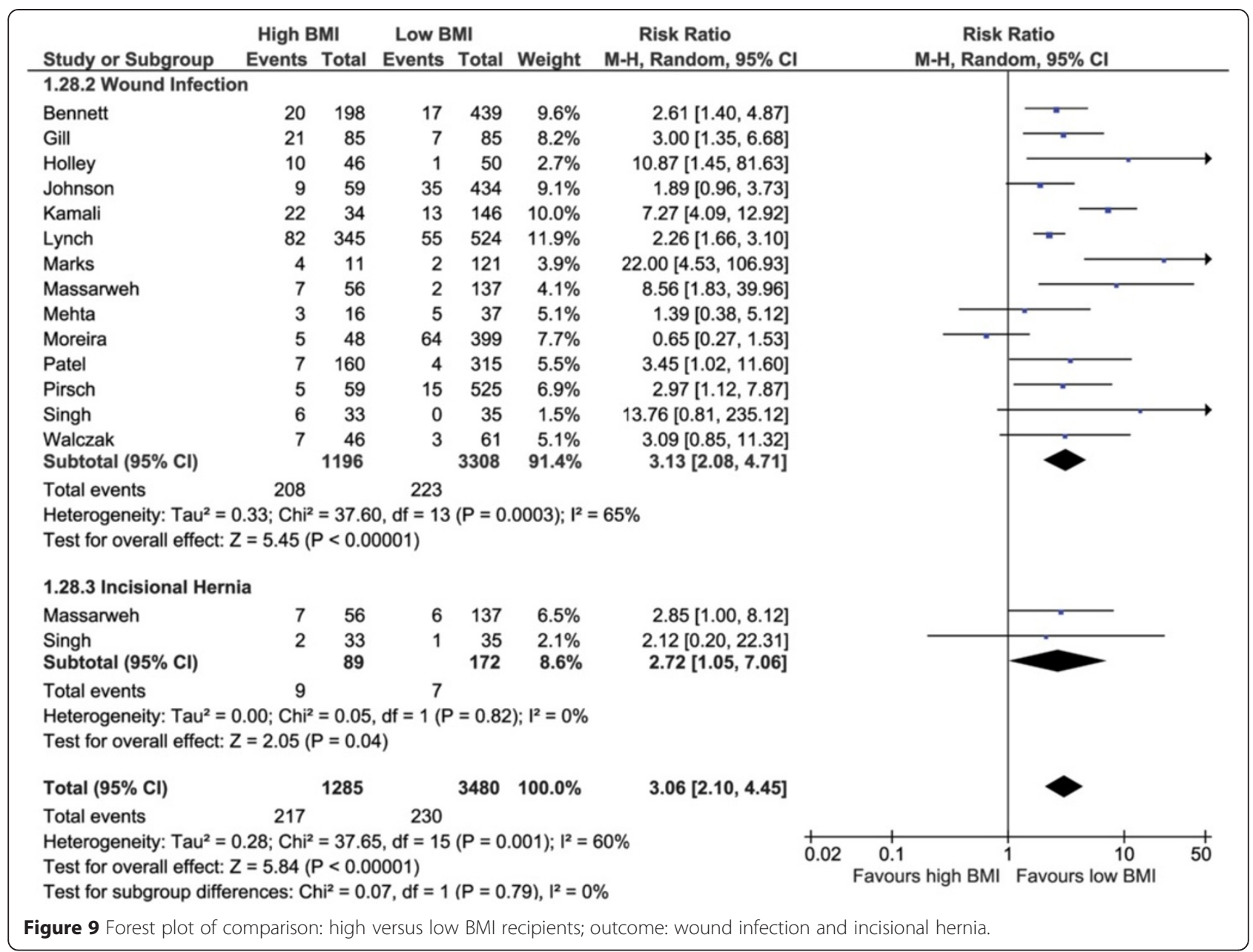

of the included studies. Potentially, several types of bias have been introduced in this analysis. The individual studies are prone to sampling bias because of the fact that they are observational studies. It is possible that, due to publication bias, the results have become skewed. However, based on funnel plot analyses (data not shown), we can safely state that publication bias is minimal. Another limitation is that not all studies have clearly specified the definition of certain outcome measures. For example, not all studies mention whether or not cases of acute rejection are, in fact, biopsy proven or the used definition of DGF. This may introduce bias in the analyses leading to heterogeneity. Moreover, only a few studies defined whether the transplanted kidneys were from live or deceased donors (donation after circulatory death or donation after brain death), which is a confounding factor in the pooled analysis of DGF. It would be interesting to have this specific information, to see whether the hypothesis that high BMI recipients have better outcome when receiving a kidney from a living donor or a standard criteria 'donation after brain death' donor kidney can be confirmed. In line of this limitation, also the 'pre-transplant' status of a recipient is of importance; whether he or she was transplanted pre-emptively or was on haemo- or peritoneal dialysis prior to transplantation has an impact on the outcome after RT.

It would be interesting if future studies would include other parameters that take into account the fat distribution of a recipient, as the BMI does not; for example, the waist circumference or hip-waist-ratio [115]. It could be that outcome would change if these parameters were correlated to outcome of RT recipients.

\section{Conclusions}

Based on our results, we make the following recommendations:

- RT candidates should not be excluded for transplantation on the basis of BMI alone. 


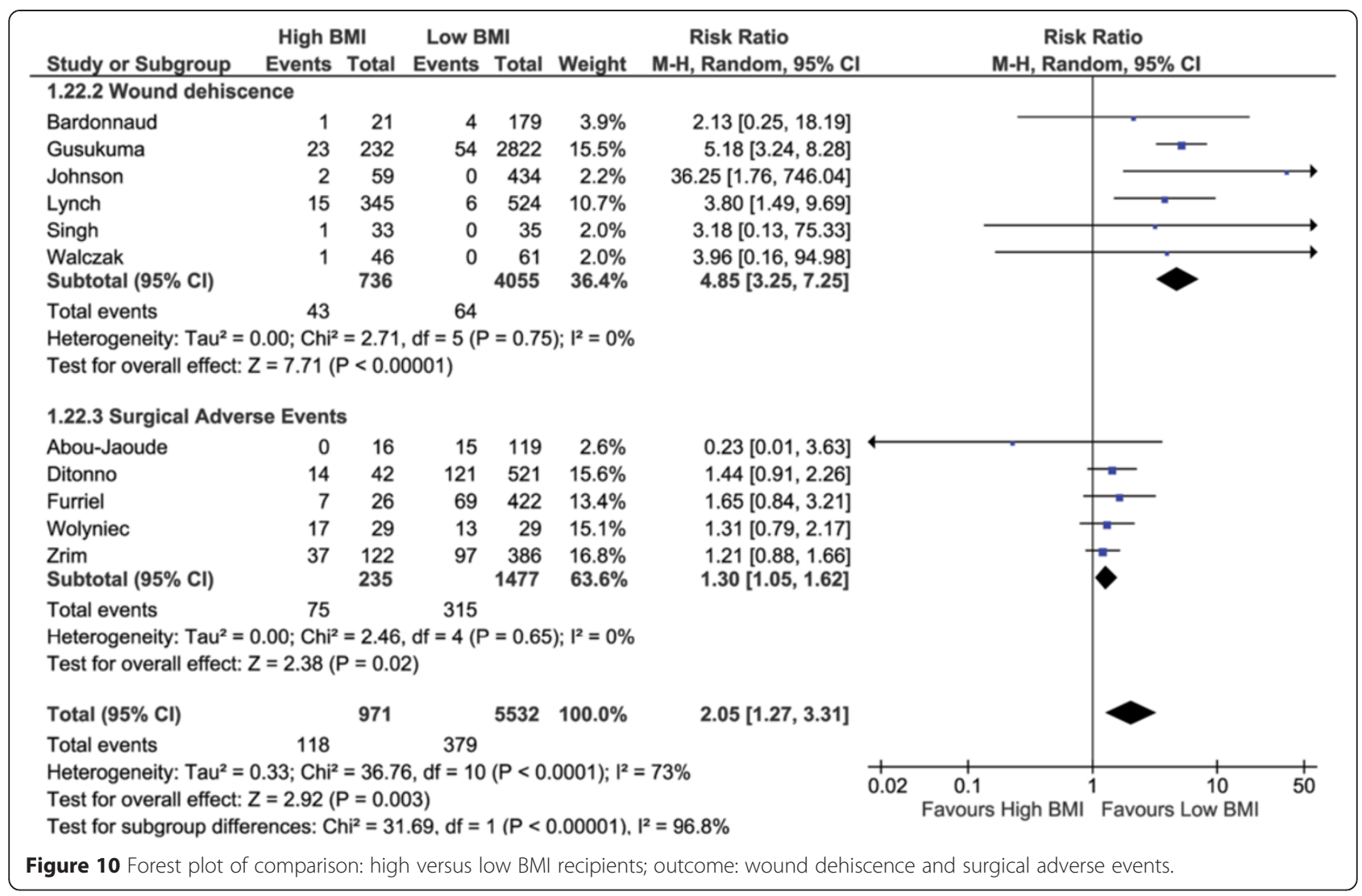

- High BMI renal transplant candidates should be referred to high-volume/tertiary referral centres in order to keep knowledge about these category of patients centralized.

- Informed consent procedures for obese RT candidates should include the risk profiles associated with obesity and RT outcome.

- Both patients and clinicians should be aware of the importance of weight loss prior to transplantation.

- (Morbidly) obese RT candidates should be informed about all possible weight reduction methods, ranging from dietary restriction under supervision of a dietician to the option of bariatric surgery.

- Obese RT candidates with a BMI between 30 and 35 should be referred to conventional methods of weight reduction, with help of a dietician.

- Obese RT candidates with a BMI $>35$ and comorbidities or a BMI $>40$ should be referred

Table 3 Outcome parameters with no significant differences

\begin{tabular}{llll}
\hline Outcome parameter & Studies & RR $(\mathbf{C l})$ & $\boldsymbol{P}$ value \\
\hline Lymphoceles & $4[29,40,69,72]$ & $1.74(0.74-4.11)$ & 0.20 \\
Hematoma & $5[48,55,69,72,78]$ & $0.89(0.34-2.34)$ & 0.82 \\
\hline
\end{tabular}

$\mathrm{RR}$, Risk ratio; $\mathrm{Cl}$, Confidence interval. for bariatric surgery, based on bariatric guidelines. Based on our experience, this could pose some difficulties for dialysis patients because of the required diet prior to bariatric surgery and age limits for bariatric surgery. Some bariatric centres have a maximum age limit of 60 for bariatric surgery. However, a large part of ESRD patients is over 60 years old. For these reasons, in our opinion, ESRD patients with morbid obesity cannot be compared to 'regular' morbid obese individuals.

- Ideally, in high BMI RT candidates, the process of weight reduction should be initiated several years before RT to ensure an adequate time period for remedial measures to become effective.

- Despite the poorer outcome of RT in these patients, the survival benefit of RT over dialysis needs to be emphasized. Therefore, we need to maximize our efforts for obese ESRD patients to get access to RT, and develop strategies to reduce the risks associated with RT in this patient category.

- Innovations in surgical techniques should be stimulated. For example, robot-assisted techniques for implantation could be promising for this specific patient category [116]. 


\section{Additional file}

\section{Additional file 1: Search strings.}

\section{Abbreviations}

BMI: Body mass index; Cl: Confidence interval; CMV: Cytomegalovirus; ESRD: End-stage renal disease; GRADE: Grades of Recommendation, Assessment, Development and Evaluation; KDIGO: Kidney Disease Improving Global Outcomes; NODAT: New onset diabetes after transplantation; OR: Odds ratio; PRISMA: Preferred Reporting Items for Systematic Reviews and Meta-Analyses; RR: Risk ratio; RT: Renal transplantation.

\section{Competing interests}

The authors declare that they have no competing interests.

\section{Authors' contributions}

JAL participated in the design of the study, evaluated studies for inclusion, performed the statistical analysis and data interpretation, and wrote the manuscript. MGHB participated in the design of the study, data interpretation, and helped to draft the manuscript. JNMIJ participated in the design and coordination of the study and helped to draft the manuscript. FJMFD conceived the study idea, participated in the design of the study, evaluated studies for inclusion, and helped to draft and supervised the writing of the manuscript. All authors read and approved the final manuscript.

\section{Acknowledgements}

We thank Wichor Bramer for his expert assistance with the systematic literature search and our colleagues at the Centre of Evidence in Transplantation Network, Professor Sir Peter Morris, and Liset Pengel, PhD, for their useful comments on the manuscript

\section{Author details}

'Department of Surgery, division of HPB \& Transplant Surgery, Erasmus MC, University Medical Center Rotterdam, 's Gravendijkwal 230, PO BOX 2040, 3000, CA Rotterdam, The Netherlands. 'Department of Nephrology, Erasmus MC, University Medical Center Rotterdam, 's Gravendijkwal 230, PO BOX 2040, 3000, CA Rotterdam, The Netherlands.

Received: 12 January 2015 Accepted: 31 March 2015

Published online: 12 May 2015

\section{References}

1. Espejo B, Torres A, Valentin M, Bueno B, Andres A, Praga M, et al. Obesity favors surgical and infectious complications after renal transplantation. Transplant Proc. 2003;35:1762-3.

2. Cannon RM, Jones CM, Hughes MG, Eng M, Marvin MR. The impact of recipient obesity on outcomes after renal transplantation. Ann Surg. 2013:257:978-84

3. The Renal Association Assessment of the Potential Kidney Transplant Recipient. The Renal Association. 2011. http://www.renal.org/guidelines/modules/ assessment-of-the-potential-kidney-transplant-recipient\#sthash.fyh0cWpM.dpbs

4. Turner C, Nogueira J. The effect of obesity on allograft outcomes in a single-center cohort of living renal transplant recipients. Am J Transplant. 2007;7:464.

5. Eckel RH, Krauss RM. American Heart Association call to action: obesity as a major risk factor for coronary heart disease. AHA Nutrition Committee Circulation. 1998:97:2099-100

6. The practical guide: identification, evaluation, and treatment of overweight and obesity in adults. US Department of Health and Human Services Public Health Service, National Institutes of Health. Bethesda, MD: NIH: National Heart, Lung, and Blood Institute; 2000

7. Young JB, Neumayer $\mathrm{H}-\mathrm{H}$, Gordon RD. Pretransplant cardiovascular evaluation and posttransplant cardiovascular risk. Kidney Int Suppl. 2010;118:S1-7.

8. Gore JL, Pham PT, Danovitch GM, Wilkinson AH, Rosenthal JT, Lipshutz GS, et al. Obesity and outcome following renal transplantation. Am J Transplant. 2006:6:357-63.

9. Aalten J, Christiaans MH, De Fijter H, Hene R, Homan Van Der Heijde J, Roodnat J, et al. The influence of obesity on short- and long-term graft and patient survival after renal transplantation. Transplant Int. 2006;19:901-7.
10. Meier-Kriesche HU, Vaghela M, Thambuganipalle R, Friedman G, Jacobs M, Kaplan B. The effect of body mass index on long-term renal allograft survival. Transplantation. 1999;68:1294-7.

11. Glanton CW, Kao TC, Cruess D, Agodoa LY, Abbott KC. Impact of renal transplantation on survival in end-stage renal disease patients with elevated body mass index. Kidney Int. 2003;63:647-53.

12. Tzamaloukas AH, Saddler MC, Murata GH, Malhotra D, Sena P, Simon D, et al. Symptomatic fluid retention in patients on continuous peritoneal dialysis. J Am Soc Nephrol. 1995;6:198-206.

13. Buchwald $H$, Avidor $Y$, Braunwald $E$, Jensen MD, Pories W, Fahrbach $K$, et al. Bariatric surgery: a systematic review and meta-analysis. JAMA. 2004;292:1724-37.

14. Maggard MA, Shugarman LR, Suttorp M, Maglione M, Sugerman HJ, Livingston EH, et al. Meta-analysis: surgical treatment of obesity. Ann Intern Med. 2005;142:547-59.

15. Modanlou KA, Muthyala U, Xiao H, Schnitzler MA, Salvalaggio PR, Brennan DC, et al. Bariatric surgery among kidney transplant candidates and recipients: analysis of the United States renal data system and literature review. Transplantation. 2009:87:1167-73.

16. Takata MC, Campos GM, Ciovica R, Rabl C, Rogers SJ, Cello JP, et al. Laparoscopic bariatric surgery improves candidacy in morbidly obese patients awaiting transplantation. Surg Obes Relat Dis. 2008;4:159-64. Discussion 64-5.

17. Szomstein S, Rojas R, Rosenthal RJ. Outcomes of laparoscopic bariatric surgery after renal transplant. Obes Surg. 2010;20:383-5.

18. Gill JS, Lan J, Dong J, Rose C, Hendren E, Johnston O, et al. The survival benefit of kidney transplantation in obese patients. Am J Transplant 2013;13:2083-90.

19. Nicoletto BB, Fonseca NKO, Manfro RC, Gonçalves LFS, Leitão CB, Souza GC Effects of obesity on kidney transplantation outcomes: a systematic review and meta-analysis. Transplantation. 2014;98:167-76.

20. Higgins JPT, Green S, editors. Cochrane Handbook for Systematic Reviews of Interventions Version 5.1.0 [updated March 2011]. The Cochrane Collaboration. 2011.

21. Moher D, Liberati A, Tetzlaff J, Altman DG, PRISMA Group. Preferred reporting items for systematic reviews and meta-analyses: the PRISMA statement. BMJ. 2009;339:b2535.

22. Obesity and overweight. World Health Organisation. Updated March 2011. http://www.who.int/mediacentre/factsheets/fs311/en/.

23. Brozek J, Oxman A, Schünemann H. GRADEpro. Version 3.2 for Windows. 2008.

24. Kidney Disease: Improving Global Outcomes Transplant Work Group. KDIGO clinical practice guideline for the care of kidney transplant recipients. Am J Transplant. 2009;9 (Suppl 3):S1-155.

25. Dudley C, Harden P. Renal Association Clinical Practice Guideline on the assessment of the potential kidney transplant recipient. Nephron Clin Pract. 2011;118:c209-24.

26. Abramowicz D, Cochat P, Claas FHJ, Heemann U, Pascual J, Dudley C, et al. European Renal Best Practice Guideline on kidney donor and recipient evaluation and perioperative care. Nephrol Dial Transplant. 2014. Ahead of print.

27. Campbell S, Pilmore H, Gracey D, Mulley W, Russell C, McTaggart S, et al. KHA-CARI guideline: recipient assessment for transplantation. Nephrology (Carlton). 2013;18:455-62.

28. Abou-Jaoude MM, Nawfal N, Najm R, Honeidi M, Shaheen J, Almawi WY. Effect of pretransplantation body mass index on allograft function and patient survival after renal transplantation. Transplant Proc. 2010:42:785-8.

29. Bardonnaud N, Pillot P, Lillaz J, Delorme G, Chabannes E, Bernardini S, et al. Outcomes of renal transplantation in obese recipients. Transplant Proc. 2012:44:2787-91.

30. Begov I, Akkina S, Benedetti E, Tang I. Obesity does not adversely affect the outcomes of kidney transplantation. Am J Transplant. 2013;13:261.

31. Bennett WM, McEvoy KM, Henell KR, Pidikiti S, Douzdjian V, Batiuk T. Kidney transplantation in the morbidly obese: complicated but still better than dialysis. Clin Transplant. 2011;25:401-5.

32. Chang SH, Coates PTH, McDonald SP. Effects of body mass index at transplant on outcomes of kidney transplantation. Transplantation. 2007:84:981-7.

33. Chow KM, Szeto CC, Leung CB, Lui SF, Tong YF, Li PKT. Body mass index as a predictive factor for long-term renal transplant outcomes in Asians. Clin Transplant. 2006;20:582-9. 
34. Cockbain AJ, Hakeem A, Hostert L, Attia M, Ahmad N, Newstead C, et al. Obesity is associated with poorer outcomes following renal transplantation. Transplantation. 2012;94:893.

35. Curran SP, Famure O, Li Y, Kim SJ. Increased recipient body mass index is associated with acute rejection and other adverse outcomes after kidney transplantation. Transplantation. 2014:97:64-70.

36. Ditonno P, Lucarelli G, Impedovo SV, Spilotros M, Grandaliano G, Selvaggi FP, et al. Obesity in kidney transplantation affects renal function but not graft and patient survival. Transplant Proc. 2011;43:367-72.

37. Dobbels F, Skeans MA, Snyder JJ, Tuomari AV, Maclean JR, Kasiske BL. Depressive disorder in renal transplantation: an analysis of medicare claims. Am J Kidney Dis. 2008;51:819-28.

38. Farooq U, Alshraideh Y, Orlando G, Rogers J, Farney A, Stratta R. Does high recipient $\mathrm{BMI}$ influence outcomes in deceased donor kidney transplantation? A paired donor kidney analysis. Am J Transplant. 2014;14:74.

39. Furriel F, Parada B, Campos L, Moreira P, Castelo D, Dias V, et al. Pretransplantation overweight and obesity: does it really affect kidney transplantation outcomes? Transplant Proc. 2011;43:95-9.

40. Gill IS, Hodge EE, Novick AC, Steinmuller DR, Garred D. Impact of obesity on renal transplantation. Transplant Proc. 1993;25:1047-8.

41. Gill J, Johnston O, Dong J, Rose C, Gill J. Novel risk factors for death after kidney transplant failure. Am J Transplant. 2013;13:130.

42. Grosso G, Corona D, Mistretta A, Zerbo D, Sinagra N, Giaquinta A, et al. The role of obesity in kidney transplantation outcome. Transplant Proc. 2012:44:1864-8.

43. Gusukuma LW, Harada KM, Baptista APM, Alencar MRP, Freitas TVS, Tedesco-Silva H, et al. Clinical outcomes in obese kidney transplantation. Am J Transplant. 2011;11:364.

44. Halme L, Eklund B, Salmela K. Obesity and renal transplantation. Transplant Proc. 1995;27:3444-5.

45. Holley JL, Shapiro R, Lopatin WB, Tzakis AG, Hakala TR, Starzl TE. Obesity as a risk factor following cadaveric renal transplantation. Transplantation. 1990;49:387-9.

46. Howard RJ, Thai VB, Patton PR, Hemming AW, Reed Al, Van Der Werf WJ, et al. Obesity does not portend a bad outcome for kidney transplant recipients. Transplantation. 2002;73:53-5.

47. Impedovo SV, Palazzo S, Bettocchi C, Grandaliano G, Schena FP, Gesualdo L, et al. Effect of obesity on long-term results of renal transplantation: a single center experience. Am J Transplant. 2012;12:249.

48. Johnson DW, Isbel NM, Brown AM, Kay TD, Franzen K, Hawley CM, et al. The effect of obesity on renal transplant outcomes. Transplantation. 2002;74:675-81

49. Kamali K, Abbasi MA, Abbasi A, Mortazavi A, Seifee MH. Impact of obesity on urologic complications among unrelated living donor kidney transplants. Indian J Surg. 2010;72:211-4.

50. Karabicak I, Aytug S, Lewis S, Shah S, Sumrani N, Hayat A, et al. Long-term kidney transplant outcome in obese patients in a predominantly African American population. Clin Transplant. 2011;25:E264-70.

51. Lynch RJ, Ranney DN, Shijie C, Lee DS, Samala N, Englesbe MJ. Obesity, surgical site infection, and outcome following renal transplantation. Ann Surg. 2009;250:1014-20.

52. McGee J, Islam TM, Reid DY, Simms ER, Lee NM, Florman SS, et al. Body mass index does not influence outcomes in African-American kidney transplant patients. Am J Transplant. 2008;8:627.

53. Marcen R, Fernandez A, Pascual J, Teruel JL, Villafruela JJ, Rodriguez N, et al. High body mass index and posttransplant weight gain are not risk factors for kidney graft and patient outcome. Transplant Proc. 2007;39:2205-7

54. Marks WH, Florence LS, Chapman PH, Precht AF, Perkinson DT. Morbid obesity is not a contraindication to kidney transplantation. Am J Surg. 2004;187:635-8.

55. Massarweh NN, Clayton JL, Mangum CA, Florman SS, Slakey DP. High body mass index and short- and long-term renal allograft survival in adults. Transplantation. 2005;80:1430-4.

56. Mehta R, Shah G, Leggat JE, Hubbell C, Roman AM, Kittur DS, et al. Impact of recipient obesity on living donor kidney transplant outcomes: a singlecenter experience. Transplant Proc. 2007;39:1421-3.

57. Modlin CS, Flechner SM, Goormastic M, Goldfarb DA, Papajcik D, Mastroianni B, et al. Should obese patients lose weight before receiving a kidney transplant? Transplantation. 1997;64:599-604.
58. Molnar MZ, Kovesdy CP, Mucsi I, Bunnapradist S, Streja E, Krishnan M, et al. Higher recipient body mass index is associated with post-transplant delayed kidney graft function. Kidney Int. 2011;80:218-24.

59. Moreira TR, Bassani T, de Souza G, Manfro RC, Gonçalves LFS. Obesity in kidney transplant recipients: association with decline in glomerular filtration rate. Ren Fail. 2013:35:1199-203.

60. Papalia T, Greco R, Lofaro D, Maestripieri S, Mancuso D, Bonofiglio R. Impact of continuous value of body mass index on graft loss in overweight patients. Transplant Proc. 2010;42:1074-6.

61. Patel S, Pankewycz O, Kohli R, Said M, Alnimri M, Feng L, et al. Obesity in renal transplantation: the role of induction therapy on long-term outcomes. Transplant Proc. 2011;43:469-71.

62. Pieloch D, Dombrovskiy V, Osband AJ, Lebowitz J, Laskow DA. Morbid obesity is not an independent predictor of graft failure or patient mortality after kidney transplantation. J Renal Nutr. 2014;24:50-7.

63. Pirsch JD, Armbrust MJ, Knechtle SJ, D'Alessandro AM, Sollinger HW, Heisey DM, et al. Obesity as a risk factor following renal transplantation. Transplantation. 1995;59:631-3.

64. Powers BD, Sifontis NM, Yung E, Spurrier D, Constantinescu S, Lee I, et al. 3 year outcomes of renal transplantation in high-risk obese recipients. Am J Transplant. 2010;10:64.

65. Raiss-Jalali GA, Mehdizadeh AR, Razmkon A, Rouzbeh J, Behzadi S, Memari H, et al. Effect of body mass index at time of transplantation and weight gain after transplantation on allograft function in kidney transplant recipients in Shiraz. Transplant Proc. 2005;37:2998-3000.

66. Rajab A, Warrick J, Pelletier RP, Henry ML, Elkhammas EA, Bumgardner GL, et al. The effects of obesity on renal transplant recipients. Am J Transplant 2007;7:464.

67. Ravindra K, Irish W, Vikraman D, Castleberry A, Barbas A, Sanoff S, et al. Impact of recipient BMI: implications for ECD renal transplantation. Am J Transplant. 2013;13:195.

68. Schwarznau A, Matevossian E, Novotny A, Stangl M. Outcome of living donor renal transplantation in obese recipients. Transplant Proc. 2008;40:921-2.

69. Singh D, Lawen J, Alkhudair W. Does pretransplant obesity affect the outcome in kidney transplant recipients? Transplant Proc. 2005;37:717-20.

70. Tang IY, Akkina S, Jairam R, Benedetti E. Outcomes of living donor kidney transplantation in morbidly obese recipients. Am J Transplant. 2011;11:101-2.

71. Tremblay S, Shields A, Kaiser T, Revollo J, Dhir U, Alloway R, et al. Absence of effect of pre-transplant body mass index on post kidney transplant outcomes. Transplantation. 2014;98:611.

72. Walczak DA, Campara M, Walczak D, McClure E, Oberholzer J, Akkina S, et al. Effect of obesity on the outcomes of $\mathrm{ABO}$ incompatible and positive crossmatch kidney transplants. Am J Transplant. 2010;10:437.

73. Weissenbacher A, Jara M, Ulmer H, Biebl M, Bosmuller C, Schneeberger S, et al. Recipient and donor body mass index as important risk factors for delayed kidney graft function. Transplantation. 2012;93:524-9.

74. Wolyniec Z, Debska-Slizien A, Rutkowski B. The influence of obesity on renal transplant outcomes - a paired kidneys analysis. Transpl ant Int. 2011;24:285.

75. Yamamoto S, Hanley E, Hahn AB, Isenberg A, Singh TP, Cohen D, et al. The impact of obesity in renal transplantation: an analysis of paired cadaver kidneys. Clin Transplant. 2002;16:252-6.

76. Zaydfudim V, Feurer ID, Moore DR, Moore DE, Pinson CW, Shaffer D. Pretransplant overweight and obesity do not affect physical quality of life after kidney transplantation. J Am Coll Surg. 2010;210:336-44.

77. Zrim S, Furlong T, Grace BS, Meade A. Body mass index and postoperative complications in kidney transplant recipients. Nephrology. 2012;17:582-7.

78. Kamali K, Abbasi MA, Behzadi AH, Mortazavi A, Bastani B. Incidence and risk factors of transplant renal artery stenosis in living unrelated donor renal transplantation. J Renal Care. 2010;36:149-52.

79. Ghoorah K, Campbell P, Kent A, Maznyczka A, Kunadian V. Obesity and cardiovascular outcomes: a review. Eur Heart J Acute Cardiovasc Care. 2014. Ahead of print.

80. Hricik DE. Metabolic syndrome in kidney transplantation: management of risk factors. Clin J Am Soc Nephrol. 2011;6:1781-5.

81. Wang $Y$, Chen $X$, Song $Y$, Caballero B, Cheskin LJ. Association between obesity and kidney disease: a systematic review and meta-analysis. Kidney Int. 2008;73:19-33.

82. Lentine KL, Delos Santos R, Axelrod D, Schnitzler MA, Brennan DC, TuttleNewhall JE. Obesity and kidney transplant candidates: how big is too big for transplantation? Am J Nephrol. 2012;36:575-86. 
83. Hasse J. Pretransplant obesity: a weighty issue affecting transplant candidacy and outcomes. Nutr Clin Pract. 2007;22:494-504.

84. Potluri K, Hou S. Obesity in kidney transplant recipients and candidates. Am J Kidney Dis. 2010;56:143-56.

85. Jindal RM, Zawada Jr ET. Obesity and kidney transplantation. Am J Kidney Dis. 2004:43:943-52

86. Srinivas TR, Meier-Kriesche HU. Obesity and kidney transplantation. Semin Nephrol. 2013;33:34-43.

87. Khwaja A, El-Nahas M. Transplantation in the obese: separating myth from reality. Nephrol Dial Transplant. 2012;27:3732-5.

88. Armstrong KA, Campbell SB, Hawley CM, Johnson DW, Isbel NM. Impact of obesity on renal transplant outcomes. Nephrology. 2005;10:405-13.

89. Molnar MZ, Kalantar-Zadeh K. Body composition and outcomes in dialysis patients and renal transplant recipients. Nephro Urol Mon. 2011;3:155-63.

90. Pischon T, Sharma AM. Obesity as a risk factor in renal transplant patients. Nephrol Dial Transplant. 2001;16:14-7.

91. Kramer H, Luke A. Obesity and kidney disease: a big dilemma. Curr Opin Nephrol Hypertens. 2007:16:237-41.

92. Rodrigo E, Fernandez-Fresnedo G, Valero R, Ruiz JC, Pinera C, Palomar R, et al. New-onset diabetes after kidney transplantation: risk factors. J Am Soc Nephrol. 2006;17:S291-5.

93. Macauley R. Weighing potential candidates for kidney transplant: the ethics of exclusion for elevated body mass index. Prog Transplant. 2012;22:369-73.

94. Dicecco SR, Francisco-Ziller N. Obesity and organ transplantation: successes, failures, and opportunities. Nutr Clin Pract. 2014;29:171-91.

95. Schold JD, Srinivas TR, Guerra G, Reed Al, Johnson RJ, Weiner ID, et al. A "weight-listing" paradox for candidates of renal transplantation? Am J Transplant. 2007:7:550-9.

96. Daly PJA, Power RE, Healy DA, Hickey DP, Fitzpatrick JM, Watson RWG. Delayed graft function: a dilemma in renal transplantation. BJU Int. 2005;96:498-501.

97. Heinbokel T, Floerchinger B, Schmiderer A, Edtinger K, Liu G, Elkhal A, et al. Obesity and its impact on transplantation and alloimmunity. Transplantation. 2013;96:10-6.

98. Tokodai K, Amada N, Kikuchi H, Haga I, Takayama T, Nakamura A. Body fat percentage as a marker of new-onset diabetes mellitus after kidney transplantation. Transplant Proc. 2013;45:1544-7.

99. Höer J, Lawong $G$, Klinge $U$, Schumpelick V. Factors influencing the development of incisional hernia: a retrospective study of 2,983 laparotomy patients over a period of 10 years. Chirurg. 2002;73:474-80.

100. Humar A, Ramcharan T, Denny R, Gillingham KJ, Payne WD, Matas AJ. Are wound complications after a kidney transplant more common with modern immunosuppression? Transplantation. 2001;72:1920-3.

101. Hoogeveen EK, Halbesma N, Rothman KJ, Stijnen T, van Dijk S, Dekker FW, et al. Obesity and mortality risk among younger dialysis patients. Clin J Am Soc Nephrol. 2012;7:280-8.

102. Chan M, Patwardhan A, Ryan C, Trevillian P, Chadban S, Westgarth F, et al. Evidence-based guidelines for the nutritional management of adult kidney transplant recipients. J Ren Nutr. 2011;21:47-51.

103. Stanfill A, Bloodworth R, Cashion A. Lessons learned: experiences of gaining weight by kidney transplant recipients. Prog Transplant. 2012;22:71-8.

104. Martin MJ, Bennett S. Pretransplant bariatric surgery: a new indication? Surg Obes Relat Dis. 2007:3:648-51.

105. Karmali S, Sweeney J, Frazier OH, Goss JA, Sherman V. P95: Adjustable gastric banding (AGB) in pre-transplant patients. Surg Obes Relat Dis. 2008:4:347-8.

106. Lin MY, Tavakol MM, Sarin A, Amirkiai SM, Rogers SJ, Carter JT, et al. Laparoscopic sleeve gastrectomy is safe and efficacious for pretransplant candidates. Surg Obes Relat Dis. 2013;9:653-8.

107. Hidalgo JE, Roy M, Ramirez A, Szomstein S, Rosenthal RJ. Laparoscopic sleeve gastrectomy: a first step for rapid weight loss in morbidly obese patients requiring a second non-bariatric procedure. Obes Surg. 2012:22:555-9.

108. Buchwald H. Consensus Conference Panel. Consensus conference statement bariatric surgery for morbid obesity: health implications for patients, health professionals, and third-party payers. Surg Obes Relat Dis. 2005;1:371-81.

109. Fried M, Hainer $V$, Basdevant A, Buchwald $H$, Deitel M, Finer N, et al. Interdisciplinary European guidelines on surgery of severe obesity. Obes Facts. 2008;1:52-9.
110. Gastrointestinal surgery for severe obesity: National Institutes of Health Consensus Development Conference Statement. Am J Clin Nutr. 1992;55(2 Suppl):615S-9S.

111. Longitudinal Assessment of Bariatric Surgery (LABS) Consortium, Flum DR, Belle SH, King WC, Wahed AS, Berk P, Chapman W, et al. Perioperative safety in the longitudinal assessment of bariatric surgery. N Engl J Med. 2009;361:445-54

112. Alexander JW, Goodman HR, Gersin K, Cardi M, Austin J, Goel S, et al. Gastric bypass in morbidly obese patients with chronic renal failure and kidney transplant. Transplantation. 2004;78:469-74.

113. Newcombe V, Blanch A, Slater GH, Szold A, Fielding GA. Laparoscopic adjustable gastric banding prior to renal transplantation. Obes Surg. 2005;15:567-70.

114. Alexander JW, Goodman H. Gastric bypass in chronic renal failure and renal transplant. Nutr Clin Pract. 2007;22:16-21.

115. Kovesdy CP, Czira ME, Rudas A, Ujszaszi A, Rosivall L, Novak M, et al. Body mass index, waist circumference and mortality in kidney transplant recipients. Am J Transplant. 2010;10:2644-51.

116. Giulianotti P, Gorodner V, Sbrana F, Tzvetanov I, Jeon H, Bianco F, et al Robotic transabdominal kidney transplantation in a morbidly obese patient. Am J Transplant. 2010;10:1478-82

\section{Submit your next manuscript to BioMed Central and take full advantage of:}

- Convenient online submission

- Thorough peer review

- No space constraints or color figure charges

- Immediate publication on acceptance

- Inclusion in PubMed, CAS, Scopus and Google Scholar

- Research which is freely available for redistribution 